\title{
Creating linkages between incomplete abortion treatment and family planning services in Kenya: What works best?
}

Julie Solo

Population Council

Achola Ominde

Margaret Makumi

Deborah L. Billings

Colette Aloo-Obunga

Follow this and additional works at: https://knowledgecommons.popcouncil.org/departments_sbsr-rh

Part of the Demography, Population, and Ecology Commons, Health Services Research Commons, International Public Health Commons, and the Women's Health Commons

How does access to this work benefit you? Let us know!

\section{Recommended Citation}

Solo, Julie, Achola Ominde, Margaret Makumi, Deborah L. Billings, and Colette Aloo-Obunga. 1998.

"Creating linkages between incomplete abortion treatment and family planning services in Kenya: What works best?" Population Council, Division of Primary Health Care, Kenya, and Ipas. 


\section{CReating Linkages betWeen INCOMPLETE ABORTION TREATMENT AND \\ FAMILY PLANNING SERVICES IN KENYA: \\ WHAT WORKS BEST?}

The Population Council

Julie Solo

The Division of Primary Health Care

Dr. Achola Ominde

Dr. Margaret Makumi

Ipas

Dr. Deborah Billings

Colette Aloo-Obunga 


\section{The Population Council}

The Population Council seeks to help improve the well-being and reproductive health of current and future generations around the world and to help achieve a humane, equitable, and sustainable balance between people and resources. The Council analyzes population issues and trends; conducts biomedical research to develop new contraceptives; works with public and private agencies to improve the quality and outreach of family planning and reproductive health services; helps governments to influence demographic behavior; communicates the results of research in the population field to appropriate audiences; and helps build research capacities in developing countries. The Council, a nonprofit, nongovernmental research organization established in 1952, has a multinational Board of Trustees; its New York headquarters supports a global network of regional and country offices.

\section{Africa OR/TA Project II}

The overall objectives of the Africa OR/TA Project II are to broaden understanding of how to improve family planning services in Sub-Saharan Africa, and to apply operations research and technical assistance to improve services by:

- increasing access to a full range of family planning services and methods;

- developing service delivery strategies that are client-oriented and acceptable to various population groups;

- improving the operations of programs to make them more efficient and financially sustainable;

- improving the quality of services;

- strengthening the capabilities of family planning program managers to use operations research to diagnose and solve service delivery problems.

This study was supported by The Population Council's Africa Operations Research and Technical Assistance Project II. The Africa OR/TA Project II is funded by the U.S. Agency for International Development (A.I.D), Office of Population Contract No. CCC-3030-C-00-3008-00, Strategies for Improving Family Planning Service Delivery. 


\section{TABle OF CONTENTS}

ACKNOWLEDGMENTS ........................................................................................................................

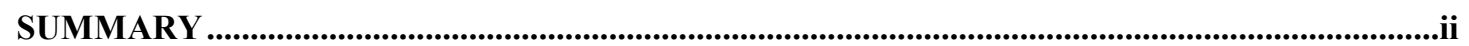

I. INTRODUCTION .......................................................................................................................................

II. STUDY DESIGN AND DATA COLLECTION ..................................................................................6

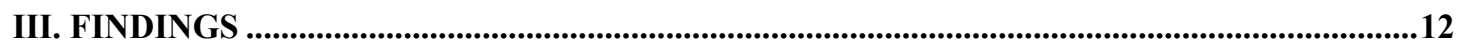

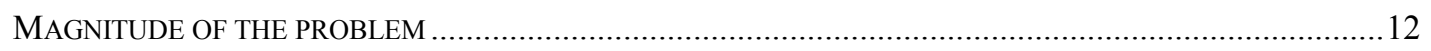

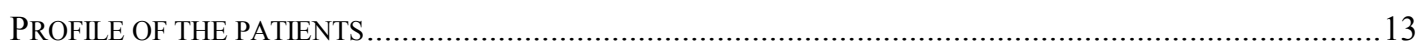

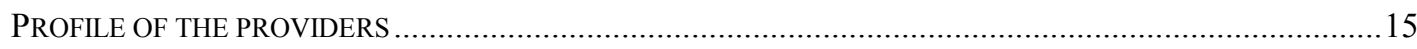

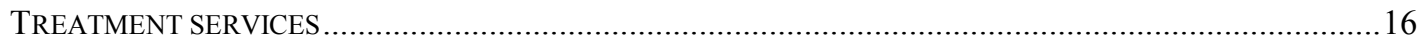

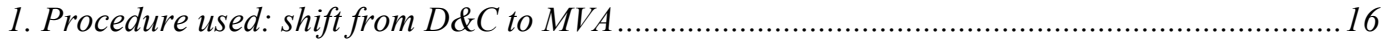

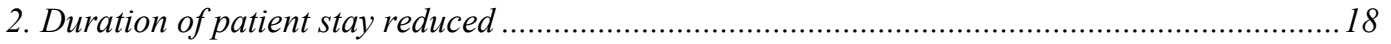

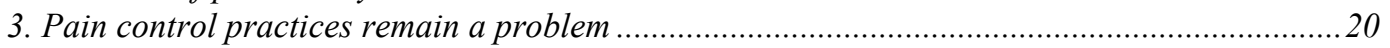

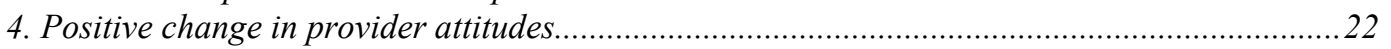

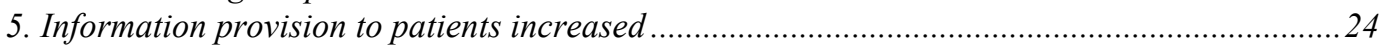

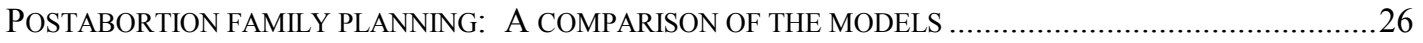

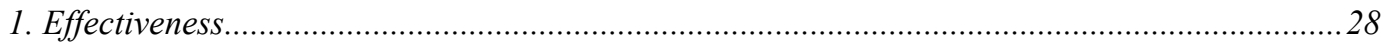

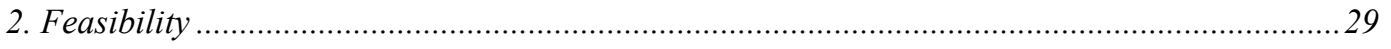

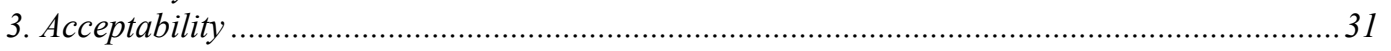

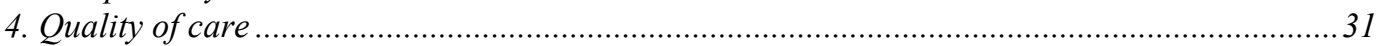

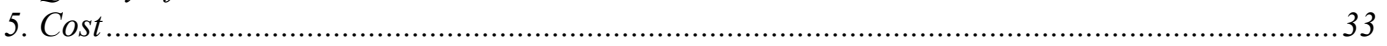

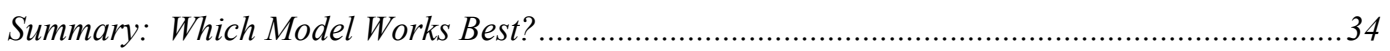

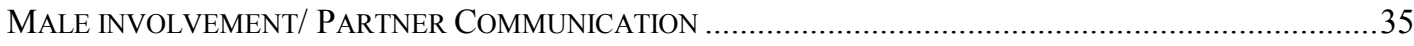

IV. CHALLENGES IN IMPLEMENTATION OF POSTABORTION CARE................................37

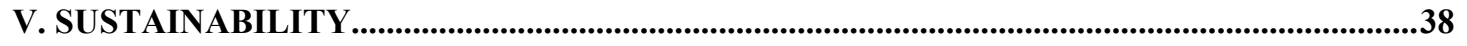

VI. DISSEMINATION WORKSHOP AND EXPANSION PLANS..................................................40

VII. FINAL RECOMMENDATIONS ....................................................................................................41

APPENDIX 1: ABORTION CASE STUDIES: WOMEN TELL THEIR STORIES......................42 


\section{ACKNOWLEDGMENTS}

The authors would like to thank the many people who made this project successful.

First of all, the researchers worked long hours, in many cases overcoming their fear of hospitals and practically becoming part of the hospital staff. Their dedication was impressive, with many of them making visits to the hospitals even after the field work was completed. Our deepest gratitude goes to Elizabeth Achieng, Njeri Kagondu, Annabel Kihuha, Eugenia King'ori, Dorcas Kungu, Mumbi Kyalo, Elizabeth Mugwe, Millie Obel, Rena Otieno, Agnes Rinyiru and Lilian Rono. In addition, we would like to express our thanks to Julius Munyao, who entered and helped with cleaning the data for both the pre and post-intervention periods.

We would also like to thank the women who allowed us to speak at length with them, even at such a difficult time, and who provided us with so much valuable information.

Of course, it is the hospital staff who implemented these new services with such enthusiasm and who also facilitated the work of the interviewers. In the words of one of the researchers,

"The ward staff were so accommodating and made me feel like one of them. They were always there to offer any assistance that I needed. Definitely this work would not have been possible without their support. I would like to take this opportunity to thank them."

We also would like to thank those responsible for implementing the intervention component of the study: Dr. Solomon Orero and Monica Oguttu who travelled to Nakuru, Mombasa and Eldoret to conduct the trainings so successfully; Lisa Bohmer and Bertha French from Ipas who organized the training of trainers, the needs assessments and purchasing of equipment, the MVA and PAFP trainings and the monitoring of services; and Grace Kihindas from the Division of Primary Health Care who provided valuable assistance in monitoring of services.

Numerous colleagues at the Population Council, most notably Ian Askew and Esther Muia, and Ipas, including Janie Benson and Dr. Khama Rogo, provided assistance throughout the course of the project, from the planning stages through the implementation and final report. Their contributions were essential to this project.

And finally, we express our gratitude to the United States Agency for International Development (USAID) without whose funding and support this study would not have been possible. 


\section{SUMMARY}

Unsafe abortion constitutes a major public health problem throughout the world, leading to high levels of maternal morbidity and mortality. It is estimated that roughly 20 million women undergo unsafe abortions every year. In addition, many women suffer complications from spontaneous abortions which often are not treated appropriately. Estimates vary, but abortion seems to account for roughly one-third of maternal mortality in the world. Millions of other women experience short and long term morbidity, such as infertility and pain.

The concept of postabortion care (PAC) has gained wide acceptance as one way to improve services provided to women with complications from spontaneous or unsafely induced abortions, to help break the cycle of repeat abortions, and to help to reduce maternal morbidity and mortality. PAC consists of three elements:

- emergency treatment services for complications of spontaneous or unsafely induced abortion

- postabortion family planning counselling and services

- links between emergency abortion treatment services and comprehensive reproductive health care

One way to improve emergency treatment is through the introduction of manual vacuum aspiration (MVA), a technique that has been shown to be safer and less costly than dilation and curettage (D\&C). Providing the second element, postabortion family planning, will enable women to avoid repeat unwanted pregnancies and therefore also avoid unsafe abortions. It will also allow women who have had spontaneous abortions to rest and wait before their next pregnancy, should they choose to do so. Links to other reproductive health care services will further help to improve women's health.

A study to test different ways of providing improved PAC services has been conducted by the Population Council's Africa Operations Research and Technical Assistance Project II in collaboration with the Division of Primary Health Care of the Kenyan Ministry of Health and Ipas. This study focused primarily on the first two components of PAC: improving emergency treatment through either the introduction or upgrading of MVA services and comparing three different models of providing postabortion family planning, as indicated in table 1 .

Table 1: Postabortion family planning models tested at each hospital

\begin{tabular}{|c|ll|}
\hline \multicolumn{2}{|c|}{ Model } \\
\hline $\begin{array}{c}\text { Model 1: FP services provided on the } \\
\text { gynae ward by gynae ward staff }\end{array}$ & $\bullet$ & Coast Provincial General Hospital \\
\hline \hline $\begin{array}{c}\text { Model 2: FP services provided on the } \\
\text { gynae ward by MCH/FP staff }\end{array}$ & $\bullet$ & Nakuru Provincial General Hospital \\
\hline \hline Model 3: FP services provided in & $\bullet$ & Eldoret District Hospital \\
MCH/FP clinic by MCH/FP staff & $\bullet$ & Nyeri Provincial General Hospital \\
\hline \hline
\end{tabular}




\section{STUdY Design}

1. Site selection. Eighteen hospitals were visited as potential study sites in April 1995. Based on caseload and infrastructure, six hospitals were selected.

2. Pre-intervention research. Between February-March and June-July, 1996, 481 incomplete abortion patients and 140 staff were interviewed at the six hospitals. This phase of the study documented the existing postabortion care services in order to provide a basis for comparison when evaluating the new services implemented as part of the intervention.

3. Intervention. The intervention consisted of three elements: training in MVA and postabortion family planning; provision of equipment and supplies; and reorganization of services. The trainings were conducted in September-October, 1996, with monitoring occurring from November 1996 up to January 1997.

4. Post-intervention research. Researchers were present at the six hospitals from March 10-May 2, 1997 to evaluate the impact of the intervention. Sources of data include: 1) structured interviews with 106 providers involved in postabortion care, 319 incomplete abortion patients prior to discharge, and 92 male partners of patients; 2) logbook reviews; 3) feasibility questionnaires administered to Medical Superintendents and Hospital Matrons; 4) cost study worksheets; and 5) daily logs of researchers.

\section{FINDINGS}

Magnitude of the problem. Researchers completed logsheets to document the caseloads of incomplete abortion and the proportion of gynecological ward admissions related to this problem as an indicator of the magnitude of the problem. On average, over one third ( 35 percent) of gynecological ward admissions were due to incomplete abortion (489/1404). This ranged from a low of 29 percent to a high of 46 percent. This could be an underestimate since in one hospital a number of the patients were classified as having a threatened abortion but later were treated for incomplete abortion.

Profile of the patients. Characteristics among the women interviewed, such as age, marital status, parity, previous pregnancy losses and preferred timing of the next birth were comparable between the pre and post-intervention periods. It is important to emphasize the variety among these patients; the profile of an incomplete abortion patient goes beyond the young, single school girl that is typically described by many providers. In particular, there are a large number of women over age 30 (22 and 17 percent, respectively, in the pre and post-intervention periods) and a high number of married women (over two-thirds).

Profile of the providers. The majority of providers interviewed in the pre and postintervention periods were nurses (67 and 72 percent, respectively), with most stationed on the gynecological ward (57 and 80 percent) or the $\mathrm{MCH} / \mathrm{FP}$ clinic (22 and 18 percent). Again, characteristics of the providers were similar in the two research 
phases. The proportion trained in MVA and postabortion family planning had increased, as these trainings were part of the intervention; 37 percent were trained in MVA in the post-intervention period as compared with 27 percent, and the proportion trained in postabortion family planning increased from six percent to 27 percent.

\section{Treatment services}

Procedure used: shift from D\&C to MVA. In the baseline, 63 percent of the women interviewed were treated with MVA, while 37 percent were treated with D\&C. The proportion of women interviewed treated with MVA increased to 95 percent in the post-intervention period.

Duration of patient stay reduced. One important benefit to MVA is that it can be performed in a minor theatre since general anesthesia is not necessary. This allows for the creation of small rooms near or on the gynecological ward for treatment of incomplete abortion. As part of the intervention, MVA rooms were either set up or renovated at all sites. This was an important factor in a dramatic decrease in the time patients spent on the ward from arrival to discharge. Based on observations as part of a cost study, this time decreased at all sites; for example, in Mombasa average duration decreased from 60 hours to 21 hours.

Pain control practices remain a problem. The experience of pain during the procedure was found to be a major problem during the baseline phase of this study. In the postintervention period, women still experienced pain during their treatment, and almost none were given any medication to ease this pain. As a result, 98 percent said that they experienced pain during the procedure, and 60 percent described this as extreme, while 32 percent considered it moderate and eight percent said it was a minimal amount of pain. These figures were very similar to the baseline figures of 61, 28 and 11 percent, respectively. However, it appeared that were improvements in verbal reassurance being given by providers to the patients during the procedure, and this seemed to have an effect on women's reactions to the pain.

Positive change in provider attitudes. There was a noticeable difference in provider attitudes towards incomplete abortion patients. In the baseline, almost half (46 percent) of the providers interviewed described provider-patient interactions as poor, while in the post-intervention interviews, less than one-third (31 percent) described them this way. Similarly, the proportion describing relations as good increased from 36 percent in the baseline to 55 percent. Providers stated that the training they received as part of this study helped in creating this change.

Information provision to patients increased. There were improvements in the information that is given to incomplete abortion patients, according to interviews with these patients. For example, in the baseline, only 13 percent were told that they could have an almost immediate return to fertility, while this increased significantly to 41 percent in the post-intervention period. The percent of women told what to do if they developed a problem after discharge increased from seven percent to 16 percent. Although these are significant increases, the majority of women treated for abortion complications still leave the hospital without vital reproductive health information. 


\section{Postabortion family planning: a comparison of the models}

Postabortion family planning counselling and provision of methods were introduced at each of the hospitals. Though this linkage was new to the hospitals, providers embraced it as an important addition to their services and patients were very pleased to be receiving family planning as part of their hospital stay. Three different models of providing postabortion family planning were implemented in six $\mathrm{MOH}$ hospitals and were compared in terms of effectiveness, feasibility, acceptability and quality of care.

Effectiveness. As the following figure indicates, model 1 was the most effective in providing family planning counselling to patients. Almost all women in model 1 sites (92 percent) received counselling as compared with 62 and 54 percent in models 2 and 3 , respectively. In addition, a higher percentage of those who decided to begin using family planning actually left the hospital with a method.

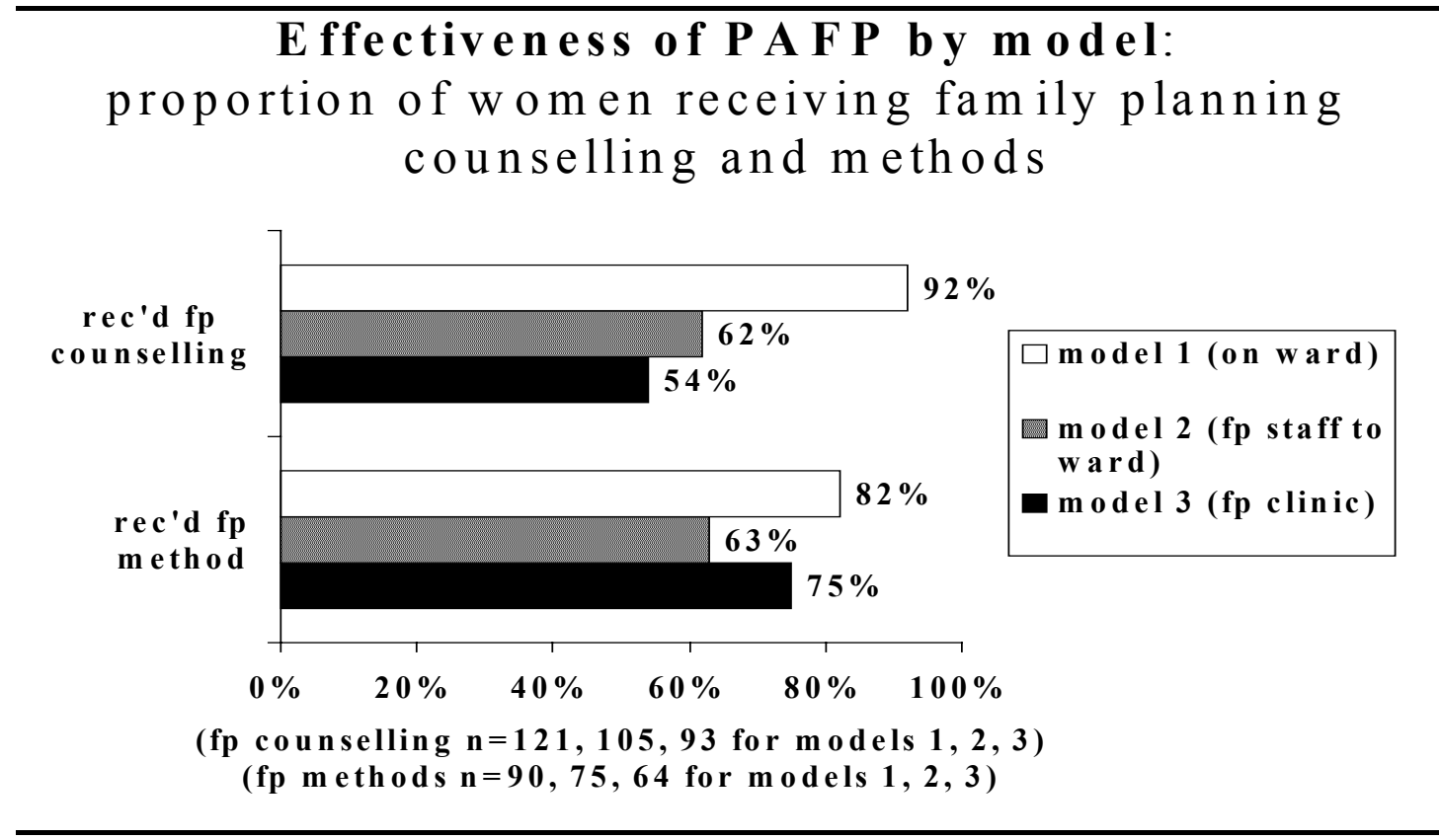

Feasibility. Model 1 was the easiest to set up, in part because it did not require coordination between the gynae ward and the MCH/FP clinic, as models 2 and 3 do. However, there were additional inputs needed for providing postabortion family planning on the ward. Those sites implementing models 1 or 2 had to create counselling spaces on the ward to ensure women's privacy and confidentiality; this was done either by using a previously unused room, by creating partitioning, or reorganizing space. In addition, there was a need to obtain contraceptive methods to provide on the ward. This did not prove to be a problem for any of the sites, as they were able to get supplies of pills, condoms and injectables from the $\mathrm{MCH} / \mathrm{FP}$ clinic.

Acceptability. Both providers and patients found the timing of PAFP (typically after treatment and before discharge) and the staff providing these services to be appropriate and acceptable. Location, however, was not acceptable according to 23 percent of providers. Of these 24 providers, 21 were at sites offering PAFP services 
in the $\mathrm{MCH} / \mathrm{FP}$ clinic. The problem most commonly mentioned was that the distance from the ward to the clinic is too long which is a burden to both patients and staff.

Quality of care. About two-thirds (64 percent) of women who received a family planning method left the hospital with the combined pill. The second most common method was the injectable (20 percent), followed by the condom (11 percent). Women were also asked about information they received on their chosen method of family planning. In general, model 3 sites performed better than both models 1 and 2 . For example, 71 percent were told about side effects at model 3 sites, while this proportion dropped to 51 percent for model 1 and 45 percent for model 2 sites. It is worth noting that there was variation between sites, and in fact, one of the model 1 sites performed as well as the model 3 sites.

Summary. Model 1 (provision of postabortion family planning on the ward by ward staff) was the easiest to set up, the most effective and the most acceptable of the three models. Model 3 ranked highest on various indicators of quality of care, though one of the model 1 sites performed as well. At sites implementing models 2 or 3, providers expressed the idea that it would be preferable to have ward staff offer PAFP on the ward - that is, to shift to model 1. Overall, we recommend that model 1 be implemented at sites when possible and note that added emphasis may need to be placed on family planning counselling during the training of gynae ward staff.

Male involvement. Almost one third (29 percent) of women's husbands/partners were interviewed regarding postabortion care services, after obtaining consent first from the women and then from their partners. Few men (14 percent) received any information about their wives' condition, and of those who did not, most (94 percent) would have liked to. They were primarily interested in learning why their partner had lost the pregnancy ( 82 percent) and how to avoid this in the future (47 percent). Few men received family planning counselling (15 percent), though most ( 92 percent) would have liked to and most women (93 percent) would have liked to have their husbands/partners receive family planning counselling.

Sustainability. Providers were asked whether they felt that MVA and postabortion family planning services would continue over the next year. Seventy-one percent felt that MVA services would continue, 18 percent said it would depend, nine percent thought services would not continue and three percent did not know. The reasons for this continuity include the positive aspects of MVA and the current supply of instruments. The main problem in continuing services is maintaining the supply of MVA kits. Many suggested allocating cost sharing money to cover the cost of purchasing these kits. Most felt that PAFP services would continue (89 percent). These providers noted that such services had become part of hospital routine and the staff were dedicated to providing the services. Six percent said it would depend, one percent said they would not and five percent did not know. Sustainability is also dependent on whether supplies on contraceptives remain constant.

Next Steps. At the dissemination workshop held on September 11-12, 1997, recommendations were made (see section VII of this report) and provincial level plans for expansion of PAC services were developed by each hospital. In addition to 
national expansion in Kenya, it is expected that findings from this study will inform regional efforts in improving postabortion care. 


\section{INTRODUCTION}

Unsafe abortion constitutes a major public health problem throughout the world. It is estimated that roughly 20 million women undergo unsafe abortions every year $^{1}$, defined by the World Health Organization as a procedure for terminating an unwanted pregnancy either by persons lacking necessary skills or in an environment lacking the minimal medical standards or both. ${ }^{2}$ Approximately 70,000 women die annually from complications related to unsafe abortions. ${ }^{3}$ While Latin America has the highest rate of unsafe abortion, and Asia has the highest absolute number, it is African women who are most likely to die when they undergo unsafe abortion. ${ }^{4}$

In Kenya, as throughout the world, the health consequences of unsafe abortion for women of reproductive age are significant. Access to abortion is severely restricted in Kenya and is only legally permitted in cases where it is necessary to save the life of the woman. Hospital-based studies in Nairobi have shown that unsafely induced abortion accounts for as much as 35 percent of maternal mortality and at least 50 percent of hospitals' gynecological admissions. ${ }^{5}$ These figures underestimate the true extent of the problem, however, since they represent only those women who make it to hospitals for treatment; women who seek services from private providers or through other means are excluded from these estimates, as are women who do not seek or who lack access to services. In addition, these figures tend to focus on induced abortion and therefore exclude women arriving at public facilities with complications resulting from a spontaneous abortion.

1 Abortion: Tabulation of Available Data on the Frequency and Mortality of Unsafe Abortion, $2^{\text {nd }}$ Ed. World Health Organization, (WHO), Geneva, 1994.

2 The Prevention and Management of Unsafe Abortion, Report of a Technical Working Group, World Health Organization, (WHO), Geneva, 1993.

Abortion: Tabulation of Available Data on the Frequency and Mortality of Unsafe Abortion.

$4 \quad$ What Can you do? Postabortion Care in East and Southern Africa. Brochure developed by REDSO, USAID and The Policy Project.

5 Lema, V., S. Kamau and K. Rogo. Epidemiology of Abortion in Kenya. The Centre for the Study of Adolescence. Nairobi, Kenya. 1989. Rogo, Khama. Induced Abortion in Kenya. Paper prepared for IPPF. Centre for the Study of Adolescence. Nairobi, Kenya. 1993. 
The Safe Motherhood Initiative, now reaching its tenth anniversary, calls for a worldwide effort to reduce maternal mortality and morbidity so that women can live healthier and more productive lives. The Government of Kenya's recent launch of its National Strategy for Reproductive Health Care (NSRHC) incorporates the goals of the Initiative and pays particular attention to the need to "strengthen facilities at appropriate levels for the management of complications of unsafe abortion" and to prevent unwanted pregnancy, as outlined in Kenya's Health Policy Framework. ${ }^{6}$

These two interventions are primary components of postabortion care (PAC), a package of services aimed at improving health care for women experiencing abortion complications. The concept of PAC has gained wide acceptance as one way to improve services provided to women with complications from spontaneous or unsafely induced abortions, to help break the cycle of repeat abortions, and to help to reduce maternal morbidity and mortality. It consists of three elements:

- emergency treatment services for complications of spontaneous or unsafely induced abortion

- postabortion family planning counselling and services

- linking emergency abortion treatment services and comprehensive reproductive health care

One way to improve emergency treatment is through the introduction of manual vacuum aspiration (MVA), a technique that has been shown to be safer and less costly than dilation and curettage (D\&C). Anecdotal, as well as empirical evidence from this study illustrates the high prevalence of repeat abortion; almost one quarter (24 percent) of women interviewed in this study had experienced previous pregnancy losses. Providing the second element, postabortion family planning, will enable women to avoid repeat unwanted pregnancies and therefore also avoid unsafe abortions. It will also allow women who have had spontaneous abortions to rest and wait before their next pregnancy, should they choose to do so. Links to other reproductive health care services will further help to improve women's health.

$6 \quad$ Ministry of Health, Kenya. National Strategy for Reproductive Health in Kenya.

Government of Kenya, 1996. Ministry of Health, Kenya. Kenya's Health Policy Framework.

Government of Kenya, 1994. 
Currently these linkages are rarely found in health settings in most of the world. In addition, the majority of hospitals still rely on $\mathrm{D} \& \mathrm{C}$ for the treatment of incomplete abortion. Although D\&C will always be necessary for women with more advanced gestations (MVA is recommended for use up to 12 weeks gestation), MVA can be an important way to improve the quality of services, increase access through providing services at lower levels of health facilities and reduce costs to health systems.

Following the international endorsement of PAC at the International Conference on Population and Development (ICPD) in Cairo in 1994, there has been increased attention and effort directed towards initiating and implementing PAC services all over the world. The recently revised reproductive health guidelines of the Kenyan Ministry of Health (MOH) include a section on postabortion care. These guidelines stress the following:

"Abortion is a common problem and often occurs under unsafe conditions. After an abortion, women are liable to get pregnant within the first ten days. Service providers must provide counselling and services to postabortion patients at the first available opportunity. ",

The Population Council's Africa Operations Research and Technical Assistance (OR/TA) Project II has collaborated with the Kenyan MOH and Ipas in conducting a study to test different ways of providing improved PAC services, including creating linkages between incomplete abortion treatment and family planning services. The findings from this study will provide important information to the $\mathrm{MOH}$ for the actual implementation of PAC services which are outlined in the national guidelines. In addition to improving emergency treatment through either the introduction or upgrading of MVA services, three different models of providing postabortion family planning were tested, as illustrated in table 1.

7 Ministry of Health, Division of Primary Health Care, Government of Kenya. Reproductive Health/Family Planning Policy Guidelines and Standards for Service Providers. Revised June, 1997. 


\section{Table 1: Postabortion family planning models tested at each hospital}

\begin{tabular}{|l|c|l|}
\hline \multicolumn{2}{|c|}{ MVA Sites } & \multicolumn{1}{c|}{ Model } \\
\hline $\begin{array}{l}\text { Coast Provincial General } \\
\text { Hospital, Mombasa }\end{array}$ & $\begin{array}{c}\text { Model 1: FP services } \\
\text { provided on the gynae ward } \\
\text { by gynae ward staff }\end{array}$ & $\begin{array}{l}\text { New Nyanza Provincial } \\
\text { General Hospital, Kisumu }\end{array}$ \\
\hline $\begin{array}{l}\text { Nakuru Provincial } \\
\text { General Hospital }\end{array}$ & $\begin{array}{c}\text { Model 2: FP services } \\
\text { provided on the gynae ward } \\
\text { by MCH/FP clinic staff }\end{array}$ & Meru District Hospital \\
\hline Eldoret District Hospital & $\begin{array}{c}\text { Model 3: FP services } \\
\text { provided in MCH/FP clinic } \\
\text { by MCH/FP staff }\end{array}$ & $\begin{array}{l}\text { Nyeri Provincial General } \\
\text { Hospital }\end{array}$ \\
\hline
\end{tabular}

These three models varied by where services were offered and who offered the services. In model 1 , family planning counselling and methods were provided on the gynecological ward by ward staff. In model 2 , these services were also provided on the ward but by staff from the MCH/FP clinic. Model 3 involved escorting the patients from the ward to the $\mathrm{MCH} / \mathrm{FP}$ clinic where they received family planning services. 


\section{Kenya Postabortion Care OR Study Sites}

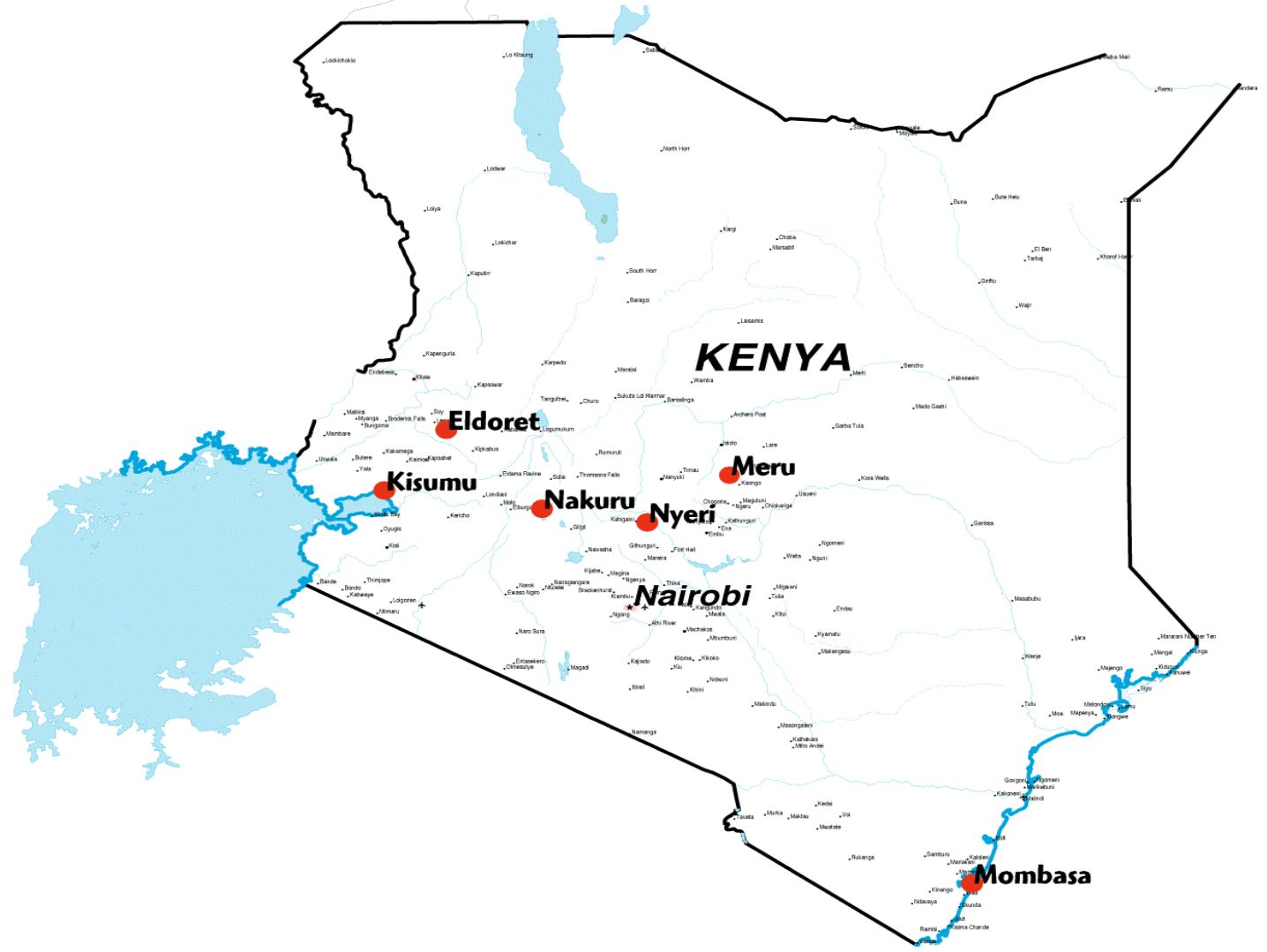

During the baseline data collection period, sites were defined as MVA or D\&C sites, depending on the primary evacuation method in the hospital. This enabled comparisons to be made between facilities where MVA services needed to be upgraded and postabortion family planning services added with hospitals where both MVA and postabortion family planning services needed to be initiated. However, it should be noted that MVA services were sometimes disrupted at "MVA sites," particularly when syringes and cannulae were not available or necessary consumable supplies were out of stock. When this occurred, hospitals resorted to treating all patients with D\&C. This has been taken into account in the analysis. 


\section{Study Design ANd Data Collection}

This study aimed to test and compare the effectiveness, feasibility, acceptability, quality of care and cost of alternative approaches to emergency treatment of abortion complications integrated with family planning in Kenya. Alternative approaches were introduced and implemented at each of the study sites. Intensive data collection throughout the project provided information to evaluate and compare the approaches. This study focused on improving services to incomplete abortion patients, including women arriving with complications from both spontaneous and induced abortions.

The study consisted of four main components: 1) site selection; 2) baseline research; 3) intervention, including training, site upgrading and reorganization of services; and 4) post-intervention research.

\section{Site selection}

During this phase, 18 hospitals were visited as potential study sites based on preliminary information regarding caseloads of incomplete abortion in order to select six sites to participate in the study. Based on caseload and infrastructure, six hospitals were selected. ${ }^{8}$ Of these six hospitals, three were designated as MVA sites and three were considered D\&C sites, since they were primarily relying on this method for treatment of incomplete abortion. It was necessary to select hospitals with high enough caseloads to obtain a large sample of women to evaluate the different models of postabortion family planning. Findings from this phase of the study highlighted the lack of postabortion family planning services in spite of the fact that providers thought that these services should be offered. While 86 percent of providers interviewed felt that women treated for incomplete abortion should always be given family planning information, only five percent said that this was routinely done.

$8 \quad$ See phase I report for more details. Solo, Julie, Esther Muia and Khama Rogo. Testing alternative approaches to providing integrated treatment of abortion complications and family planning in Kenya: Findings from Phase I. The Population Council. Nairobi, Kenya. August, 1995. 


\section{Pre-intervention research}

The baseline research consisted of interviewing 481 incomplete abortion patients and 140 staff between February-March and June-July, 1996. This phase of the study documented the existing postabortion care services in order to provide a basis for comparison when evaluating the new services implemented as part of the intervention. Researchers were present at the hospitals over two continuous six to eight week periods. This provided rich qualitative data to put the quantitative data in context. The following box details some of the main findings from the baseline. ${ }^{9}$

\section{BASELINE FINDINGS}

$\checkmark$ Incomplete abortion patients were of a wider variety than providers perceived when asked to describe the "typical" patient (see table 4);

$\checkmark$ Waiting times for treatment varied greatly, from a few hours to a number of days. The majority of patients waited over a day to receive treatment;

$\checkmark$ Among the women interviewed, almost two-thirds (63 percent) were treated with $M V A$, while the 37 percent were treated with $D \& C$;

$\checkmark$ The majority of patients experienced what they defined as an extreme amount of pain during the procedure, and they were typically not given any medication or verbal reassurance to ease this pain;

$\checkmark$ Negative provider attitudes toward incomplete abortion patients affected the quality of care which women received;

$\checkmark$ Patients were given minimal information or counselling from providers regarding their general health status, possible complications they might experience after the procedure, their return to fertility, and family planning;

$\checkmark$ Although women expressed a need and demand for postabortion family planning counselling and methods, these services were typically not offered to women after their treatment.

\section{Intervention}

$9 \quad$ See baseline report for more details. Ominde, Achola, Margaret Makumi, Deborah Billings and Julie Solo. Postabortion Care Services in Kenya: Baseline Findings from an Operations Research Study. The Population Council. Nairobi, Kenya. March 1997. 
The intervention consisted of three elements: a) training in MVA and postabortion family planning (PAFP); b) provision of equipment and supplies; and c) reorganization of services. Monitoring and evaluation trips to the sites were made by project monitors and Ipas trainers to help staff address problems in the delivery of services throughout the intervention period from September 1996 to January 1997.

a. Training in $M V A$ and PAFP

Trainings in both MVA and PAFP were conducted in the months of September and October, 1996. Table 2 shows the number of staff at each site who were trained in MVA or PAFP.

Table 2: Staff trained in MVA and PAFP by site

\begin{tabular}{|c|c|c|c|c|c|c|c|}
\hline \multirow{2}{*}{ MVA } & Doctors & 3 & 2 & 3 & 1 & 2 & 2 \\
\cline { 2 - 8 } & Nurses & 3 & 3 & 3 & 3 & 4 & 3 \\
\hline \hline PAFP & Nurses & 5 & 5 & 4 & 4 & 4 & 4 \\
\hline \hline & TOTALS & 11 & 10 & 10 & 8 & 10 & 9 \\
\hline
\end{tabular}

Doctor/nurse teams working on the gynae wards attended the MVA trainings to enable nurses to assist the doctors during evacuation procedures and ensure that infection control measures were followed. Initially two doctor/nurse teams from each site were to be trained in MVA, but this was not always possible due to understaffing and scheduling conflicts (table 2). Only nurses were trained in PAFP. For Nakuru, Meru, Eldoret and Nyeri (i.e., models 2 and 3) the nurses to be trained in PAFP were drawn from the MCH/FP clinic, while for Mombasa and Kisumu (model 1), they came from the gynecological wards. The following table indicates the topics covered in the trainings. 


\begin{tabular}{|ll|ll|}
\hline \multicolumn{2}{|c|}{ MVA (5 days) } & \multicolumn{2}{l|}{ Postabortion Family Planning (5 days) } \\
\hline$*$ MVA facts & $*$ & Rationale for PAFP \\
$*$ & Patient-Provider Interaction and & $*$ & Treatment of Abortion Complications \\
& Communication & $*$ & Communicating with Postabortion Clients \\
$*$ & Universal Precautions & $*$ & Management of Services \\
$*$ & Patient Assessment and & $*$ & Review of Family Planning Methods \\
& Preparation & $*$ & Effective Communication Skills \\
$*$ & Pain Control for MVA & $*$ & Introduction to Counselling (adapted from \\
$*$ & Performing the MVA Procedure & & AVSC) \\
$*$ & Complications & $*$ & The GATHER Technique (adapted from \\
$*$ & Postabortion Family Planning & & AVSC) \\
$*$ & Ipas Instrument Reuse & $*$ & Application of Counselling Techniques \\
$*$ & Quality of Care & & (role plays and case studies) \\
\hline
\end{tabular}

\section{b. Equipment and supplies}

To ensure that those trained went back to their sites and implemented MVA and PAFP services immediately, equipment and supplies were purchased through the project and delivered to the sites directly after the training. Such equipment and supplies included MVA instruments, ${ }^{10}$ sterilizers, portable lamps, gynae couches, blood pressure machines, kidney dishes, tenacula, specula, surgical gloves, tooth brushes (for cleaning the cannulae), plastic buckets, JIK and chairs. The equipment provided for each site differed somewhat based on the specific needs of the site.

\section{c. Reorganization of services}

MVA rooms were set up on or next to gynae wards in hospitals where procedures were still being conducted in theatre. Sites which already had a space set aside for the MVA procedure were given supplies to renovate the area. Equipment and supplies were also provided so that MVA services could begin immediately after the trainings. Sites implementing models 1 and 2 also had to identify and set up a separate space for counselling postabortion patients in private and had to arrange for contraceptives to be available on the ward. This was done in collaboration with the $\mathrm{MCH} / \mathrm{CP}$ clinic at each site and posed no major problems.

10 It should be noted that MVA equipment was supplied through the PAC Consortium Drawdown account and was not purchased with USAID funds. 
Linking emergency treatment with family planning services was a central aim of this intervention. To achieve this, family planning counselling and method provision mechanisms had to be introduced as a primary service for postabortion patients. For each model, staff had to reorganize time and responsibilities to provide the PAC services. In model 1, at least one trained nurse on the gynae ward had to be available to provide the family planning services to women after their treatment. For model 2, the trained nurses had to also reorganize themselves and find time to go to the gynae ward to provide PAFP counselling and services to postabortion patients. And, in model 3 the gynae ward staff had to organize to send/refer/escort postabortion patients to the MCH/FP clinic and the latter had to ensure that they provided the

necessary PAFP to these patients. Record-keeping specific to postabortion care patients was also introduced as part of the project. Each site created registers to record both MVA and PAFP service statistics.

\section{Post-intervention research}

Researchers were present at the hospitals over an eight week period from March- May, 1997 to evaluate the impact of the intervention. Sources of data include: 1) structured interviews with 106 providers involved in postabortion care, 319 incomplete abortion patients prior to discharge, and 92 male partners of patients; 2) register reviews; 3) feasibility questionnaires administered to Medical Superintendents and Hospital Matrons; 4) cost study worksheets; and 5) daily logs of researchers.

Table 3 outlines the interviews conducted during this phase of research. As in the baseline, women arriving at the hospital with incomplete abortion, without serious complications and with gestations of 16 weeks LMP or below were selected to be included in the study. Women were included in the study after interviewers obtained verbal informed consent. Women's husbands/partners were also interviewed, but only in cases where the woman first consented and then the man gave his consent. Almost one-third (29 percent) of women's partners were interviewed. In addition, researchers completed logsheets to document the daily gynecological ward admissions, daily bed occupancy and caseloads of incomplete abortion. As in the baseline, researchers kept daily diaries of their experiences at the hospitals which added depth and context to the quantitative data collected. 
Table 3: Interviews conducted during post-intervention data collection

\begin{tabular}{|l|c|c|c|}
\multicolumn{1}{c}{ Hospital } & Staff & Patients & Men (Partners) \\
\hline Eldoret & 20 & 50 & 15 \\
\hline Kisumu & 11 & 50 & 22 \\
\hline Meru & 19 & 45 & 16 \\
\hline Mombasa & 9 & 71 & 19 \\
\hline Nakuru & 18 & 60 & 6 \\
\hline Nyeri & 29 & 43 & 14 \\
\hline \multicolumn{1}{|c|}{ TOTALS } & $\mathbf{1 0 6}$ & $\mathbf{3 1 9}$ & $\mathbf{9 2}$ \\
\hline
\end{tabular}

Two additional researchers visited three sites each to document the feasibility and cost of the new services. The feasibility instrument explored the following issues: facility upgrading; staffing; procedural reorganization; patient flow; and sustainability. The cost component followed the Ipas manual for estimating costs, ${ }^{11}$ with adjustments made for the situation in Kenya and the specific cost questions addressed by this study. This manual directs the researcher to follow a patient throughout the course of her treatment at the facility. Researchers document the resources used for a patient-including bedtime, staff time and medicines used-to determine the overall cost of treatment to the facility.

11 Abernathy, M., C. Hord, L. Nicholson, J. Benson and B. Johnson. A Guide to Assessing Resource Use for the Treatment of Incomplete Abortion. IPAS. Carrboro, NC. 1993. 


\section{FINDINGS}

\section{Magnitude of the problem}

During the course of this study, information was collected from registers to assess the caseloads of incomplete abortion and the proportion of gynecological ward admissions related to this problem as an indicator of the magnitude of the problem. As shown in figure 1, on average, over one third (35 percent) of gynecological ward admissions at five of the six hospitals in the study were due to incomplete abortion $(489 / 1404) .^{12}$

It should be noted that there were sometimes difficulties in classification, particularly regarding threatened vs. incomplete abortion. ${ }^{13}$ For example, Nakuru saw large numbers of patients who were classified as threatened abortion upon arrival but later were treated with MVA for incomplete abortion. ${ }^{14}$ If we include these in the sample, the percentage of gynae ward patients who experience incomplete abortion at Nakuru increases from 29 percent to 44 percent; the overall proportion in the total sample increases to 38 percent $(536 / 1404)$. These figures are comparable to those found in other studies. Clearly, incomplete abortion accounts for a substantial proportion of gynecological admissions and is a significant problem which all hospitals in the study must address.

12 Data were not available for one of the hospitals in the study.

13 "Threatened abortion" refers to a situation where an abortion may occur. The most common sign is vaginal bleeding but the product of conception is still intact; "incomplete abortion" refers to a condition whereby an abortion has taken place but fetal tissue remains in the uterus and needs to be artificially removed.

14 One possible explanation according to some of the providers is that women went to "quacks" to obtain induced abortions and were told to go to the hospital when they started bleeding, but ended up panicking early and arriving at hospital where they were diagnosed as "threatened" rather than incomplete. 


\section{Gynae ward admissions: March 10-May 2, 1997 for five Kenyan MOH hospitals}

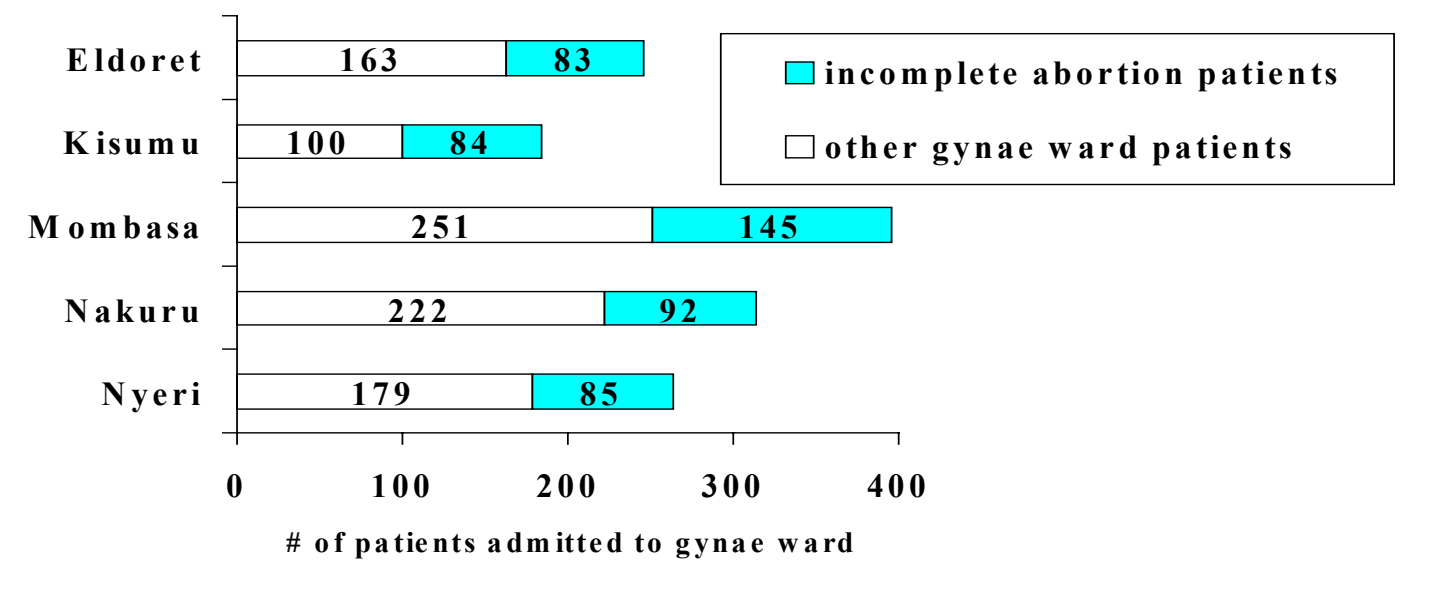

\section{Profile of the patients}

As table 4 indicates, there were no significant differences between the sociodemographic characteristics of the women interviewed in the pre-intervention and post-intervention periods. As in the baseline, it is important to emphasize the variety among these patients; the profile of an incomplete abortion patient goes beyond the young, single school girl that is typically described by many providers. In particular, there are a large number of women over age 30 (22 and 17 percent in the pre and postintervention periods, respectively) and a high number of married women. ${ }^{15}$

Most (91 percent) of the women in the sample sought medical attention at the hospital because of vaginal bleeding. Almost two-thirds (74 percent) experienced cramping/abdominal pain, while a number of women cited backache (29 percent) dizziness (20 percent), and headache (19 percent) as reasons for seeking care. It should be noted that all of the women included in the sample experienced incomplete abortion unaccompanied by other complications such as sepsis or uterine perforation. Such limitations were placed on the sample composition so that cost data could be collected in a consistent manner.

15 It is possible that the proportion married is an overestimate, as some women identify as such because of the stigma associated with being single and having an abortion. 
Table 4: Characteristics of incomplete abortion patients

\begin{tabular}{|l|c|c|}
\multicolumn{1}{|c}{ Characteristic } & $\begin{array}{c}\text { Pre-intervention } \\
(\mathbf{n = 4 8 1})\end{array}$ & $\begin{array}{c}\text { Post-intervention } \\
(\mathbf{n}=\mathbf{3 1 9})\end{array}$ \\
\hline AGE & $18 \%$ & $17 \%$ \\
$15-19$ & $38 \%$ & $42 \%$ \\
$20-24$ & $23 \%$ & $24 \%$ \\
$25-29$ & $11 \%$ & $9 \%$ \\
$30-34$ & $11 \%$ & $8 \%$ \\
$>35$ & & $32 \%$ \\
\hline PARITY & $33 \%$ & $31 \%$ \\
0 & $29 \%$ & $15 \%$ \\
1 & $15 \%$ & $21 \%$ \\
2 & $23 \%$ & $61 \%$ \\
$>2$ & & $8 \%$ \\
\hline MARITAL STATUS & $63 \%$ & $23 \%$ \\
married (monogamous) & $8 \%$ & $8 \%$ \\
married (polygamous) & $23 \%$ & $17 \%$ \\
single & $6 \%$ & $7 \%$ \\
other & $15 \%$ & $17 \%$ \\
\hline PREVIOUS PREGNANCY LOSSES & $9 \%$ & \\
1 & & $16 \%$ \\
2 or more & $22 \%$ & $22 \%$ \\
\hline USING FP AT TIME OF LAST & & $24 \%$ \\
PREGNANCY & $23 \%$ & \\
yes & $22 \%$ & \\
\hline PREFERRED TIMING OF NEXT BIRTH & $20 \%$ & \\
no more children & & \\
wait 1-2 years & & \\
wait more than 2 years & & \\
\hline
\end{tabular}

As found in the baseline research, there was a need for family planning among a significant number of these patients. Sixteen percent would not like to have any more children, while almost half would like to space their next birth; 22 percent would like to wait one to two years for their next child and 24 percent would like to wait more than two years. Among the men interviewed, these desires for stopping or spacing are fairly similar; although only eight percent would not like to have any more children, 18 percent would like to wait one to two years and 21 percent would like to wait more than two years.

Just over half of the women (51 percent) had ever used family planning methods; the pill was the most common method ( 31 percent) followed by injectables (18 percent), condoms (10 percent) and the IUD (9 percent). Seventeen percent of women were using family planning at the time they became pregnant. The majority of these women were using the pill (47 percent) or rhythm (19 percent). When men 
were asked these same questions, the proportions were quite similar: 52 percent had ever used family planning and 17 percent indicated that they were using at the time their wife/partner became pregnant.

\section{Profile of the providers}

Providers who were involved in the postabortion care process at each hospital were interviewed. This included providers who were involved in any of the following: performing or assisting with evacuation procedures; counselling women about treatment; nursing care; or family planning services for incomplete abortion patients. In both the pre and post-interventions periods, the majority of the providers interviewed were nurses, while the rest included medical officers, clinical officers and OB/GYN Specialists. Most providers were stationed on the gynecological ward or the $\mathrm{MCH} / \mathrm{FP}$ clinic. On average, providers were about 34 years old, over two-thirds were married, and most were Protestant or Catholic.

Table 5: Characteristics of providers interviewed

\begin{tabular}{|c|c|c|}
\hline Characteristic & $\begin{array}{l}\text { Pre-intervention } \\
\qquad(n=140)\end{array}$ & $\begin{array}{l}\text { Post-intervention } \\
(\mathrm{n}=106)\end{array}$ \\
\hline $\begin{array}{l}\text { DESIGNATION } \\
\text { nurses } \\
\text { medical officers } \\
\text { clinical officers } \\
\text { OB/GYN specialists } \\
\end{array}$ & $\begin{array}{c}67 \% \\
16 \% \\
10 \% \\
6 \% \\
\end{array}$ & $\begin{array}{c}72 \% \\
18 \% \\
9 \% \\
2 \% \\
\end{array}$ \\
\hline $\begin{array}{l}\text { LOCATION } \\
\text { gynecological ward } \\
\text { MCH/FP clinic } \\
\text { theatre (major or VSC) } \\
\text { whole facility (i.e., Matron) } \\
\end{array}$ & $\begin{array}{l}57 \% \\
22 \% \\
16 \% \\
5 \% \\
\end{array}$ & $\begin{array}{c}80 \% \\
18 \% \\
1 \% \\
1 \% \\
\end{array}$ \\
\hline $\begin{array}{l}\text { SOCIO-DEMOGRAPHIC } \\
\text { age (mean) } \\
\text { marital status } \\
\text { religion }\end{array}$ & $\begin{array}{c}34.7 \text { years } \\
69 \% \text { married, } 26 \% \text { single } \\
65 \% \text { Protestant } \\
31 \% \text { Catholic } \\
\end{array}$ & $\begin{array}{c}34.4 \text { years } \\
71 \% \text { married, } 26 \% \text { single } \\
71 \% \text { Protestant } \\
27 \% \text { Catholic } \\
\end{array}$ \\
\hline $\begin{array}{l}\text { VIEW ON KENYA'S ABORTION LAW } \\
\text { appropriate for the country } \\
\text { too restrictive } \\
\text { too liberal } \\
\text { no opinion }\end{array}$ & $\begin{array}{c}51 \% \\
39 \% \\
6 \% \\
3 \% \\
\end{array}$ & $\begin{array}{c}58 \% \\
36 \% \\
6 \% \\
1 \% \\
\end{array}$ \\
\hline
\end{tabular}


There were no significant differences between the pre and post-intervention samples except the location of staff within the hospital. During the baseline, theatre staff were interviewed since they had been involved in postabortion care in Mombasa and Meru. They were typically no longer involved in providing these services in the post-intervention period since MVA was now being provided outside of theatre.

Just over one quarter (27 percent) were trained in postabortion family planning, while 37 percent were trained in MVA. Both of these had increased from the baseline rates of six percent and 27 percent, respectively, due to the fact that MVA trainings were a part of the study intervention. It should be noted that not all of the providers who were interviewed had taken part in the trainings, as only a small number of providers from each site were trained during the intervention.

\section{Treatment services}

\section{Procedure used: shift from D\&C to MVA}

MVA has been recommended for use in the treatment of incomplete abortion. Numerous studies have documented that it is a highly effective method for uterine evacuation, that it is safer than D\&C and can save scarce health resources through reducing costs. ${ }^{16}$ The intervention of this study involved either introducing or upgrading MVA services at the six hospitals.

In the baseline, 63 percent of the women interviewed were treated with MVA, while 37 percent were treated with D\&C. The proportion treated with MVA increased to 95 percent in the post-intervention period $(\mathrm{p}=.0000)$. Figure 2 indicates this shift by hospital. Because of the criteria used for inclusion in the study (i.e., uterine size of 16 weeks or less), not all women were treated with MVA. It is important to note that D\&C will always be necessary for treatment of incomplete abortion patients with larger gestations. It is interesting to note that the proportion decreased slightly in Mombasa. Prior to the intervention, staff had been using MVA to treat patients with a

16 Baird, T.L., R.E. Gringle and F.C. Greenslade. MVA in the Treatment of Incomplete

Abortion: Clinical and Programmatic Experience. IPAS. Carrboro, North Carolina. 1995 
uterine size equivalent to16 weeks or less; after the intervention, only women with uterine size of 13 weeks or less were being treated with MVA.

Providers, in general, were highly satisfied with MVA to treat incomplete abortion. Seventy-one percent of providers who have assisted or performed MVA are very satisfied with the technique, while 29 percent are somewhat satisfied. This is much higher than the satisfaction expressed for $\mathrm{D} \& \mathrm{C}$; only 15 percent were very satisfied, 52 percent somewhat satisfied and one-third (33 percent) were not satisfied.

Shifting from D\&C to MVA involved not only a change in the technology used for uterine evacuation but also a reorganization of general services. Even in some sites where MVA had been used prior to the project, the intervention implemented asked providers to create an MVA space on or near the gynae ward. Overall, such reorganization has streamlined patient flow in each of the hospitals.

Figure 2

\section{Proportion of patients treated with MVA among patients interviewed at each hospital}

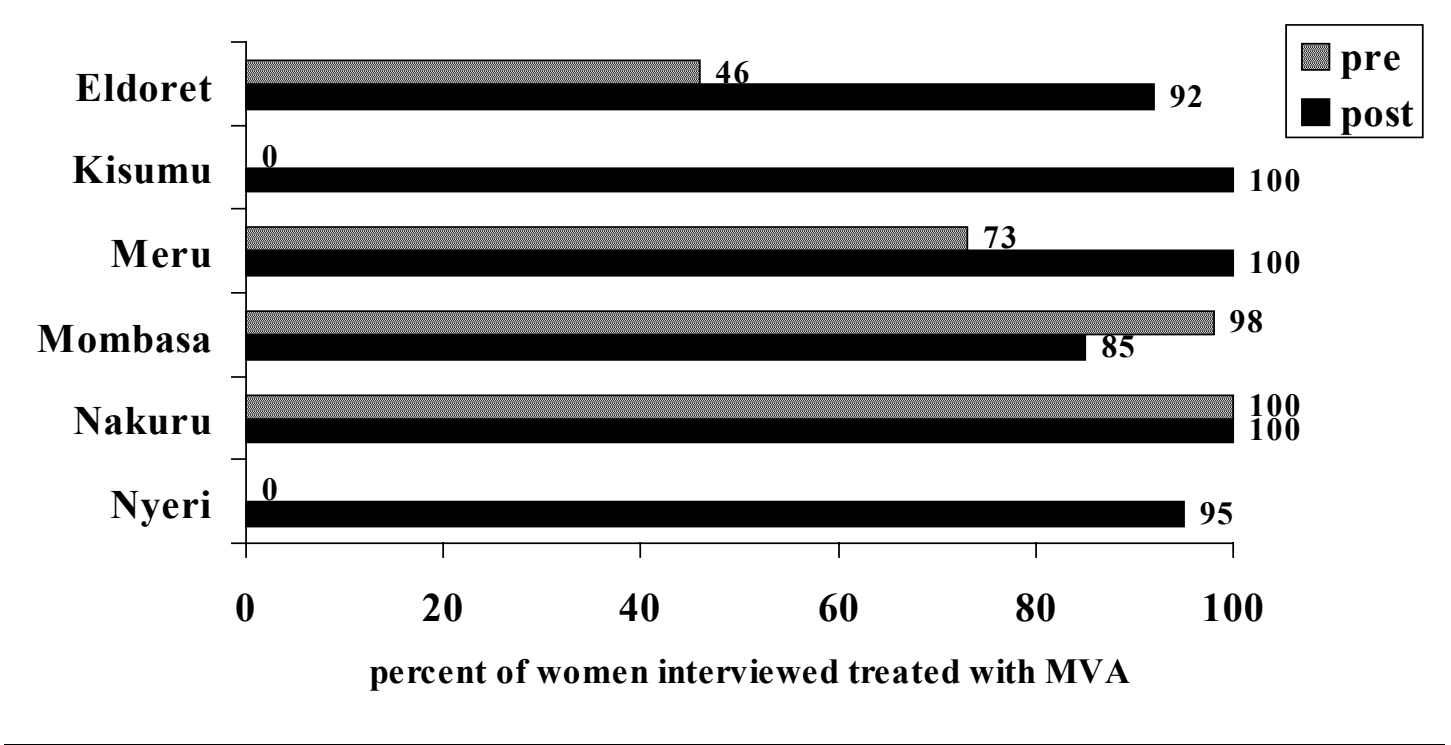


For example, in Mombasa, MVA was already being used to treat incomplete abortion, but it was being performed in the VSC theatre, which was far from the ward. The hospital has now created a minor theatre on the gynecological ward where MVA is done. This has been received quite enthusiastically by the hospital staff, as they are now able to treat patients much more efficiently as they do not have to take them to the VSC theatre to be treated. The nurses claim that having the MVA services on the ward has made things a lot easier and has gone a long way in easing their workload. They also state that infection rates of postabortion patients have decreased since women are treated more quickly after they arrive.

Similarly, Meru had been treating incomplete abortion cases in the main theatre, which was available for gynae patients on Tuesdays and Fridays. Thus women arriving on Saturday, for example, had to wait until Tuesday to be treated. They too have now created a minor theatre on the ward. The four other sites already had a room on (Nakuru and Eldoret) or adjacent to (Kisumu and Nyeri) the ward where they treated incomplete abortion cases. Efficiency at these sites also improved in many cases, due to the extra MVA kits provided.

\section{Duration of patient stay reduced}

One of the important impacts of reorganizing services, particularly in setting up MVA rooms on the gynecological ward, is the dramatic reduction in time that

patients spend in the hospital. Providers feel that this has been very helpful in relieving congestion on the ward. It should be noted that the hospitals included in this study treat incomplete abortion patients as in-patients rather than out-patients. This did not change from the pre to post-interventions periods, but the amount of time patients spent at the facility after admission to the hospital did change significantly.

A sample of patients from each site were observed and the time spent for each stage of their treatment was recorded. These data therefore detail the time spent in the hospital from arrival on the gynecological ward until discharge. 


\section{Duration of patient stay on the gynecological ward: data from cost study observations}

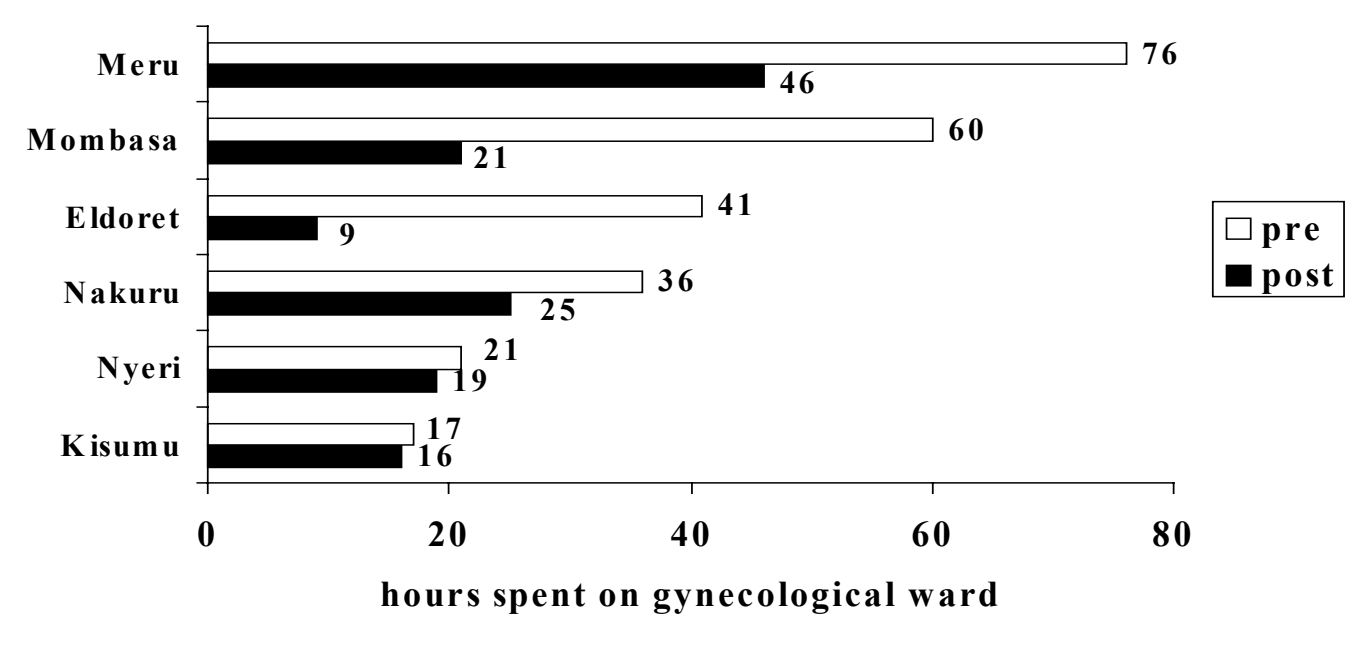

As figure 3 indicates, duration of patient stay decreased at all sites, often dramatically. For example, at Mombasa, the average amount of time spent on the gynecological ward decreased from 60 hours to just over 20 hours. The amount of time a patient spends in the hospital varies a great deal between hospitals, and even within hospitals, due to a number of factors, including the lack of services on weekends or the lack of an available trained provider. Given the sample of women included in the study, such durations are an underestimate for women who arrive with complications, such as sepsis or uterine perforation, in addition to incomplete abortion. 
Figure 4: Long stays in the hospital sometimes led to as many as three women in one bed

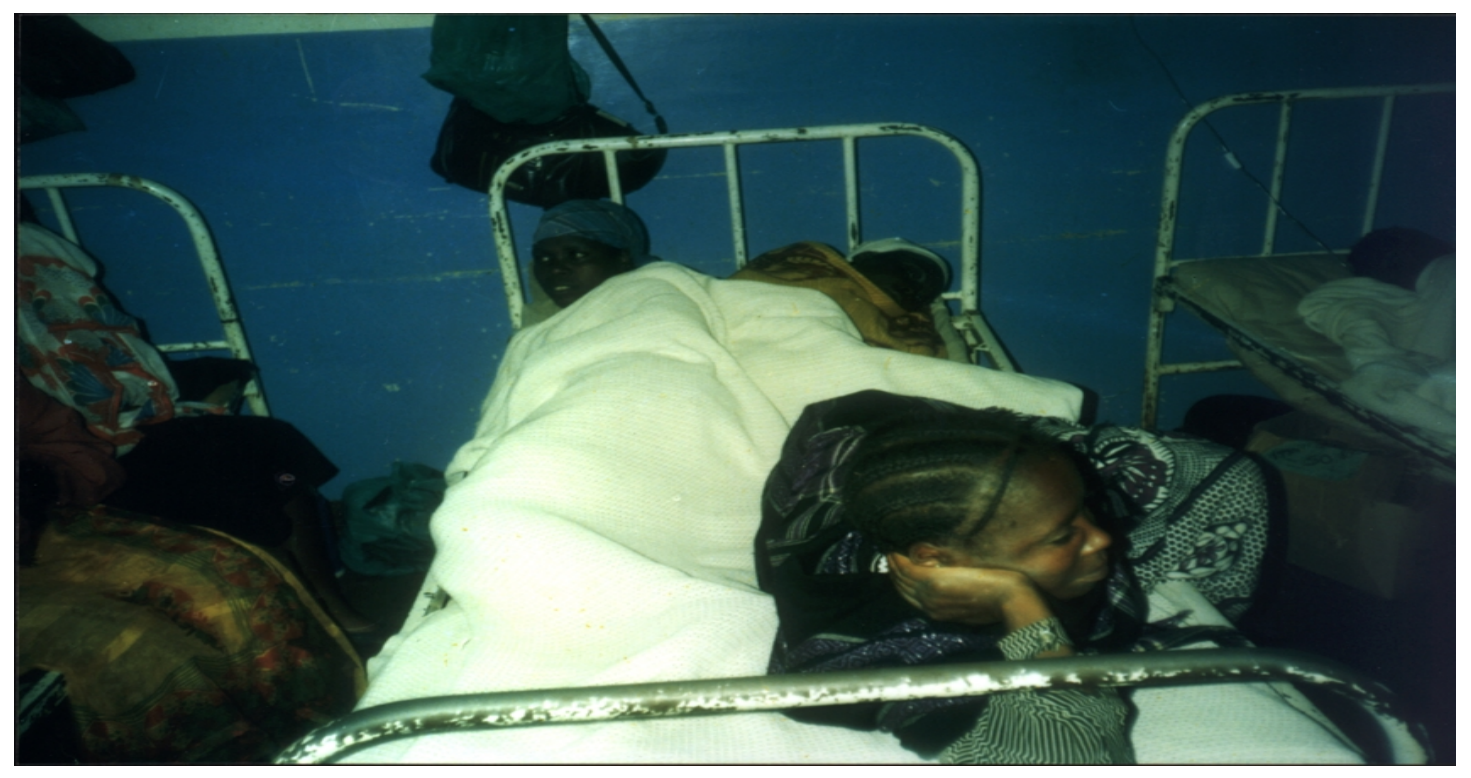

\section{Pain control practices remain a problem}

One of the benefits to MVA is that lighter levels of pain control medication are needed as compared with $\mathrm{D} \& \mathrm{C}$, thereby reducing the risk to the patient from the use of general anesthesia and requiring fewer health system resources. The general recommendation is that "gentle, supportive treatment of the patient with analgesia (anti-anxiety agent) and paracervical block is generally the best overall option for effective MVA pain control," but practices vary in different settings. ${ }^{17}$

The experience of pain during the procedure was found to be a major problem during the baseline phase of this study. In the post-intervention period, women still experienced pain during their treatment, and according to patient records, very few (three percent of MVA patients) were given any medication before or during the procedure to ease this pain. This is similar to the baseline where three percent of MVA patients received pain medication. As a result, 98 percent said that they experienced pain during the procedure, and among patients treated with MVA, 60 percent described the pain as extreme, while 32 percent considered it moderate and eight percent said it was a minimal amount of pain. These figures were comparable to

17 Margolis, Alan, Ann Leonard and Laura Yordy. "Pain Control for Treatment of Incomplete Abortion with MVA" Advances in Abortion Care, Volume 3, Number 1. IPAS. Carrboro, North Carolina. 1993. 
the baseline findings for MVA patients, where 62 percent described the pain as extreme, 27 percent moderate and 11 percent minimal.

In part, providers' relative lack of experience with MVA can account for the pain since the worst pain often occurs at the completion of the evacuation when the uterus contracts. Providers who continue aspiration longer than necessary can provoke strong contractions. Choosing not to use pain medications such as analgesias and paracervical block also adds to women's experience of pain. In fact, when asked how services could be improved, 12 percent of women interviewed pointed out the need to give pain medication.

Although there was no systematic observation guide administered by researchers, observational evidence indicates that there were improvements in pain control in terms of verbal reassurance being given after providers received training. Researchers noted providers comforting the patients during the procedure and holding their hands, which had rarely happened during the baseline data collection period. In addition, 88 percent of women indicated that a provider reassured them during the procedure (as this question was not asked in the baseline, no comparison can be made). Providers would say things like the following: "kutakuwa na uchungu kidogo lakini fumilia - there will be a bit of pain but please relax." The following entries from a researcher's log demonstrates the impact of this verbal reassurance:

Before the procedure, all the patients were given pre-procedure counselling. During the procedure the nurse assisting was very polite to patients and kept reassuring them. No patient screamed.

On this day, the nurse assisting had not been trained so that nice language was lacking as procedures took place. And guess what? Some patients screamed.

The information collected in this study was not able to measure this impact of verbal reassurance, sometimes referred to as verbal anesthesia or verbacaine. ${ }^{18}$ Some providers still stressed the idea that pain control is needed to improve the quality of services. One researcher noted the following comments from a doctor: "I strongly

18 Winkler, Judith, Elizabeth Oliveras and Noel McIntosh, editors. Postabortion Care: $A$ Reference Manual for Improving Quality of Care. Postabortion Care Consortium. 1995. 
think patients for MVA should be given injections to minimize pain. Sometimes I feel, after evacuating a patient they do not want to see my face again. A hospital should not be seen as a place where pain is going to be inflicted but rather as a place where pain should be relieved." Others expressed this same idea, and felt that the guidelines need to be clearer regarding use of low-level pain control during MVA procedures. Some expressed their frustration that the training discussed the use of pain control, but in practical sessions during the training, no pain control was used. This is an area that should be addressed more clearly in future training.

\section{Positive change in provider attitudes}

There was a notable difference in provider attitudes towards incomplete abortion patients. In the baseline, almost half (46 percent) of the providers interviewed described patient-provider interactions as poor, while in the postintervention interviews less than one-third (31 percent) described them in this way (figure 5). Similarly, the proportion describing relations as good increased from 36 percent in the baseline to 55 percent $(\mathrm{p}=.0023)$.

It is also notable that in the baseline the most common complaint from patients when asked what they would do to improve services at the hospital was to have staff change their attitudes towards the patients. This was mentioned by 25 percent of patients in the pre-intervention period, but was only referred to by 10 percent of women interviewed in the post-intervention period. Although there is still room for improvement, this change is encouraging, as there was concern after the baseline data collection that these attitudes might prove to be a barrier to improving postabortion care services and that there would be difficulties in changing attitudes. Although one training will not permanently change attitudes, it does appear that it can help to sensitize providers regarding the impact of their attitudes on patients' recovery, use of family planning and likelihood of women returning with complications from yet another abortion. 


\section{Positive change in providers' descriptions of relations with incomplete abortion patients}

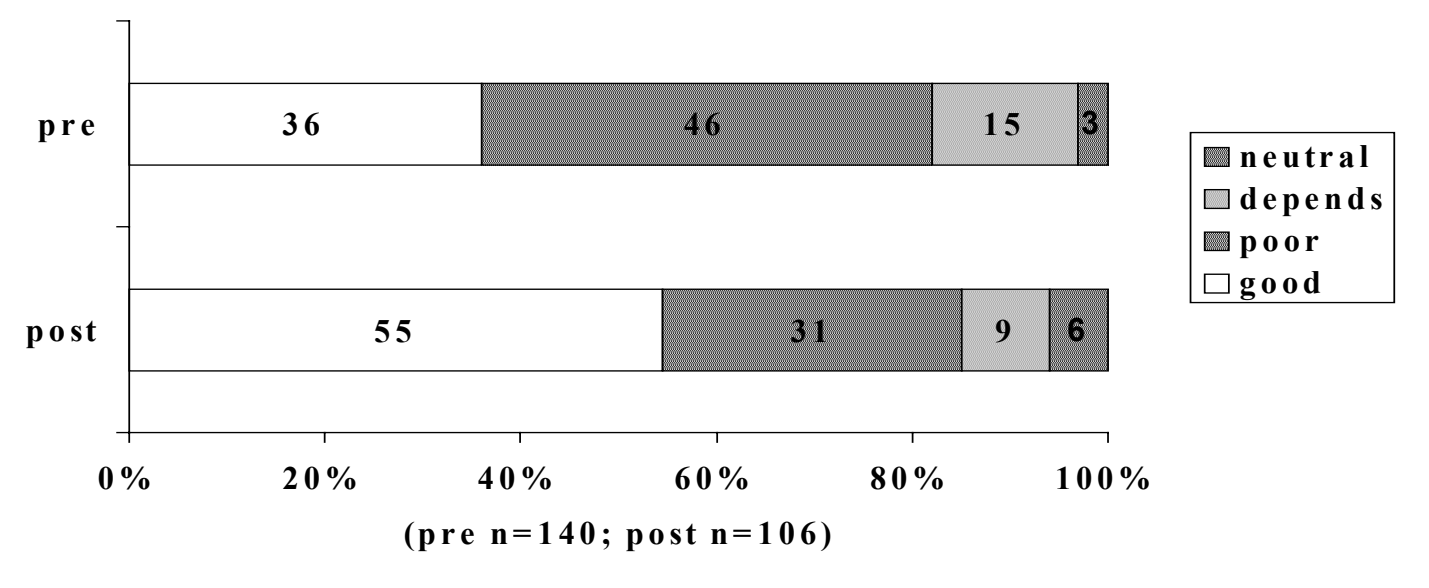

Many providers credited the training they received as part of this intervention with changing their attitudes towards these patients, as shown in the following quotes from interviews with hospital staff:

"I witnessed and assisted in the MVA procedure and my attitude toward the incomplete abortion patients has changed"

"[it] has made me change and have a good attitude towards patients who have procured an abortion whether induced or not. They all need love and care."

There also seemed to be a difference in attitudes between those who were trained and those who were not. As one provider said, "the nurses in MCH/FP have been oriented on how to attend to postabortion patients, to even have a 'heart' towards them", but then in discussing difficulties with the services explained that "the ward nurses are not taking postabortion cases seriously due to their attitudes." Providers attending the project's dissemination workshop identified positive provider attitudes as key to sustaining PAC activities in their hospitals and in the country in general. 


\section{Information provision to patients increased}

There were improvements in the information that is given to incomplete abortion patients, according to interviews with these patients. For example, in the baseline, only 13 percent were told that they could have an almost immediate return to fertility, while this increased significantly to 41 percent in the post-intervention period $(\mathrm{p}=.0000)$. This actually ranged quite a bit between sites, from a low of 18 percent to a high of 67 percent. The percent of women told about specific problems for which they should return to a health facility only increased from two percent to six percent $(\mathrm{p}=.0074)$, while the percent told what to do if they developed a problem after discharge increased from seven percent to 16 percent $(\mathrm{p}=.0001)$.

Figure 6

\section{Information provision to patients}

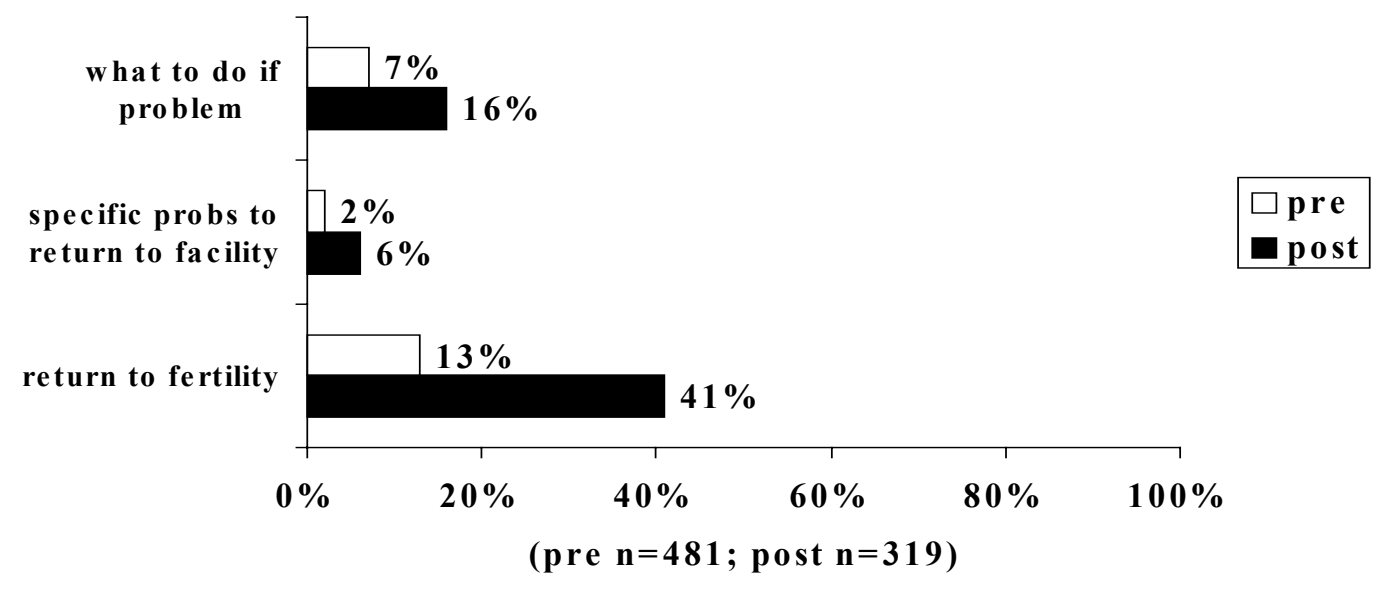

One factor contributing to the improvement in information provision is the change in provider knowledge, particularly regarding postabortion family planning. For example, 87 percent of providers in the post-intervention period knew that a woman can start using contraception immediately following an evacuation as compared with 62 percent in the baseline $(\mathrm{p}=.00017)$. Although a higher proportion of women received information subsequent to the intervention, it is still important to further improve this area, as these are essential pieces of information that women 
should receive before discharge from the hospital so that they have adequate information to address their health needs. This is an area that needs to receive greater emphasis in training.

Figure 7: Provider with patients in gynecological section of female ward, Meru District Hospital

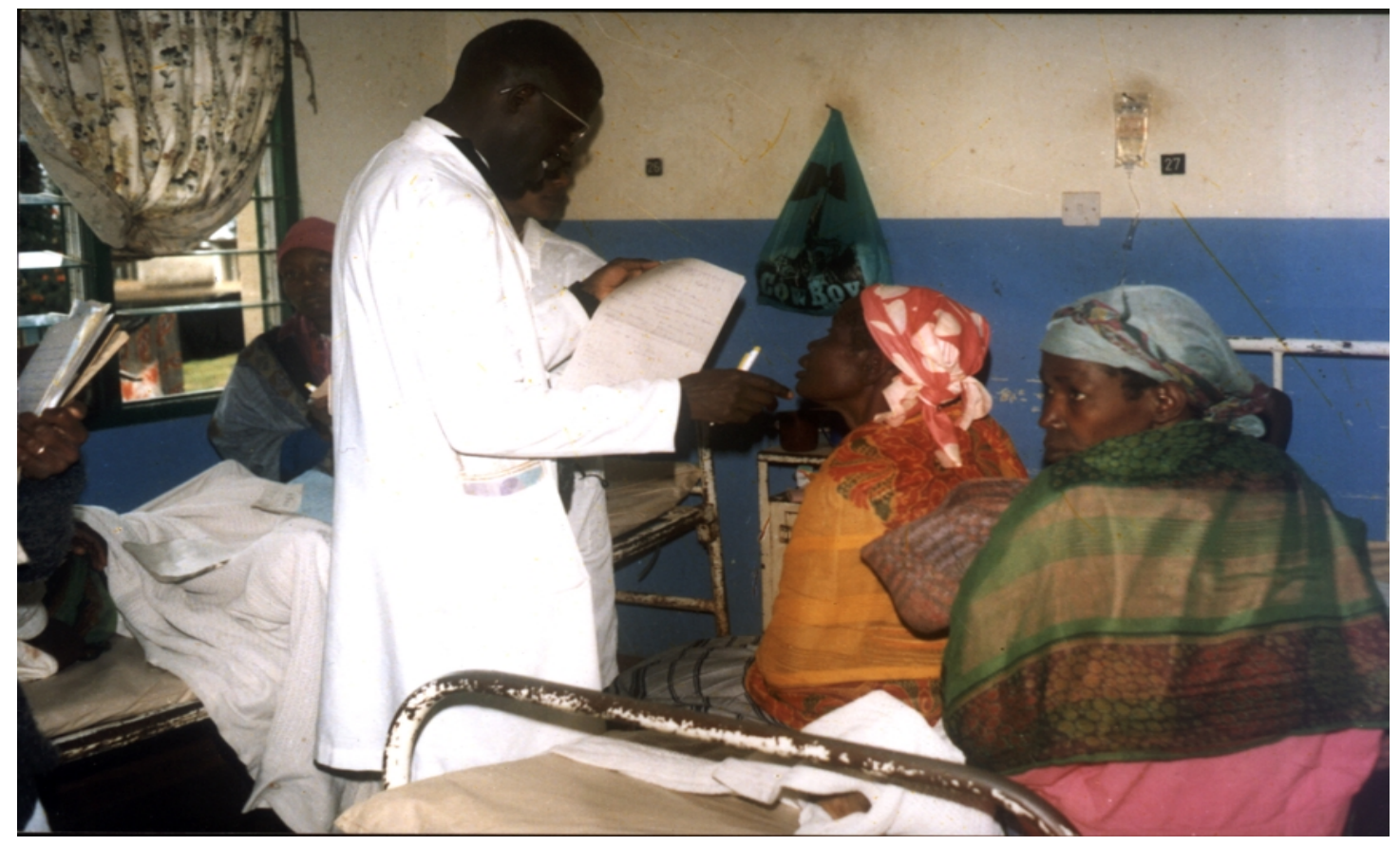




\section{Postabortion family planning: A comparison of the models}

Postabortion family planning counselling and provision of methods were introduced at each of the hospitals. Though this linkage was new to the hospitals, providers embraced it as an important addition to their services and patients were very pleased to be receiving family planning as part of their hospital stay, as the following quotes illustrate:

"the clients' response about postabortion family planning is very positive. It is helping because you get them before they leave."

"it is essential for the patients instead of them coming back with more miscarriages."

As shown in figure 8 , in the post-intervention period, 68 percent of women interviewed received family planning counselling. 69 percent decided to begin using family planning, and of these, almost three-quarters (70 percent) received a family planning method before leaving the hospital. This was a dramatic increase from the baseline, where only seven percent received family planning counselling, only 22 percent decided to begin using family planning, and of these only three percent received a method $(\mathrm{p}=.0000)$.

Figure 8

Improvements in postabortion family planning from pre-intervention to post-intervention

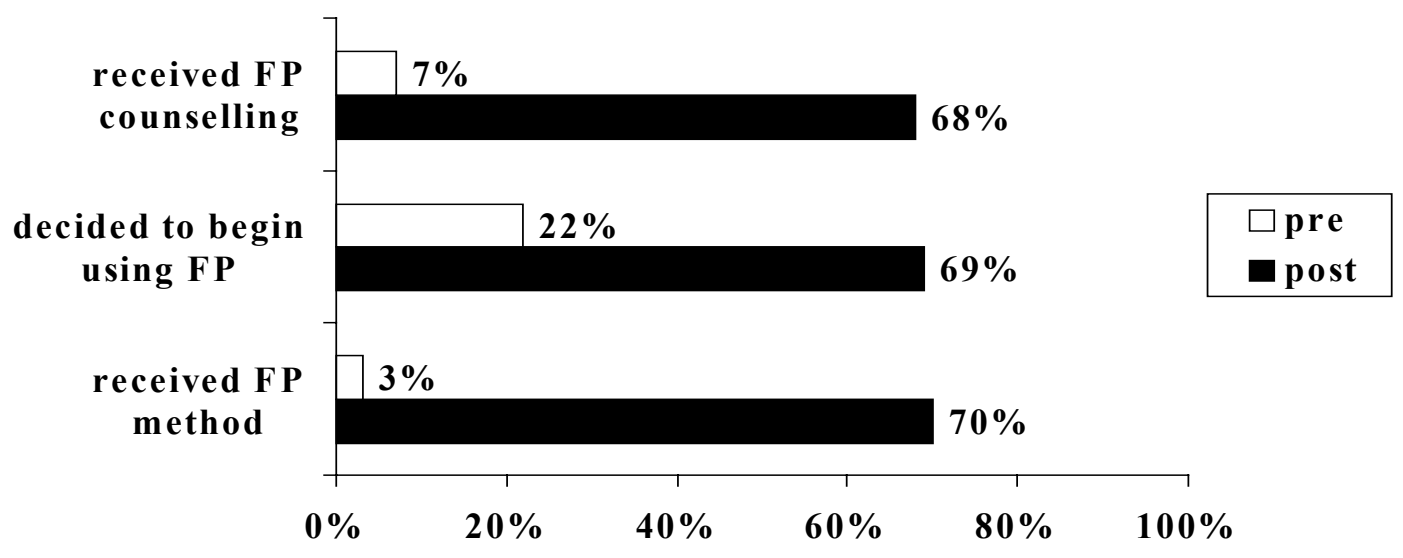

(counselling $n=419,276$; use $F P n=417,276$; received method $n=90,191$ ) 
Data for Nyeri Provincial General Hospital are excluded from figure 8, as their situation was unique. After a preliminary planning meeting held in August 1995 at the beginning of this project, staff from Nyeri were so enthusiastic about the idea of postabortion family planning services that they immediately began implementing their model. Therefore, in the baseline they were already offering these services and 98 percent of women interviewed received family planning counselling, while 62 percent decided to begin using family planning and almost all of these women (97 percent) received a family planning method before leaving the hospital. These services at Nyeri have continued successfully; in the post-intervention period, 91 percent received counselling, 88 percent decided to begin using family planning and 95 percent of these women received a method before discharge.

As stated earlier, the three models of postabortion family planning tested were as follows:

1. In model 1, family planning counselling and methods were provided on the gynecological ward by ward staff (on ward).

2. In model 2, family planning services were also provided on the ward but by staff from the MCH/FP clinic (FP staff to ward).

3. Model 3 involved escorting the patients from the ward to the MCH/FP clinic where they received family planning services (FP clinic).

Typically it was easier to initiate services in the sites where family planning was offered on the ward by ward staff. The other models involved more coordination between units, something that is certainly possible and has worked well, but is more of an involved process to start. When staff were asked what advice they would give to hospitals wishing to set up similar services, in addition to the importance of training (43 percent) and having necessary equipment (32 percent), many emphasized that they should provide family planning after MVA (21 percent), that they should give services on the ward (10 percent) and that they should put up a counselling room on the ward (11 percent).

In comparing the different models, we will focus on five dimensions: effectiveness, feasibility, acceptability, quality of care and cost. 


\section{Effectiveness}

Effectiveness is defined as the percentage of women who receive family planning counselling and, for those who decide to begin using family planning, actually leave the hospital with a method. Data presented in figure 9 clearly indicate that model 1 is more effective than the other models. Not only did more women receive counselling with model 1 , but a higher percentage of those who decided to begin using family planning actually left the hospital with a method.

Figure 9

\section{Effectiveness of PAFP by model: proportion of women receiving family planning counselling and methods}

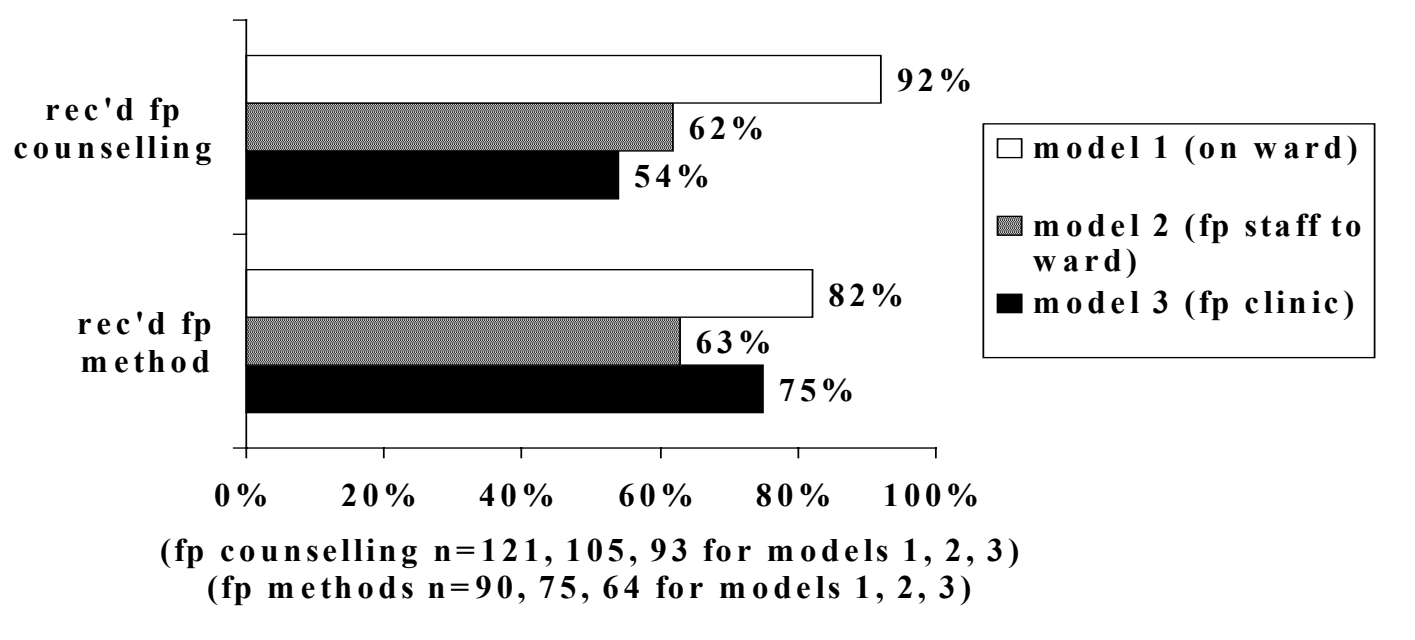

However, it is important to keep in mind the unique situation of each hospital. For example, model three did not perform as well, but this is in part due to difficulties experienced at Eldoret, as the hospital was undergoing renovations during the entire post-intervention period causing the gynecological ward to move a number of times. 
Table 6: Postabortion family planning, by hospital (post-intervention)

\begin{tabular}{|c|l|c|c|c|}
\hline \multicolumn{2}{|c}{ mospital } & $\begin{array}{c}\text { received FP } \\
\text { counselling }\end{array}$ & $\begin{array}{c}\text { decided to use } \\
\text { FP }\end{array}$ & $\begin{array}{c}\text { of those who decided to use, } \\
\% \text { who received method }\end{array}$ \\
\hline \multirow{2}{*}{ model 1 } & Mombasa & $89 \%$ & $76 \%$ & $89 \%$ \\
\cline { 2 - 5 } & Kisumu & $96 \%$ & $72 \%$ & $72 \%$ \\
\hline \hline \multirow{2}{*}{ model 2 } & Nakuru & $45 \%$ & $65 \%$ & $33 \%$ \\
\cline { 2 - 5 } & Meru & $84 \%$ & $80 \%$ & $94 \%$ \\
\hline \hline \multirow{2}{*}{ model 3 } & Eldoret & $22 \%$ & $52 \%$ & $46 \%$ \\
\cline { 2 - 5 } & Nyeri & $91 \%$ & $88 \%$ & $95 \%$ \\
\hline
\end{tabular}

If we break down the number of women receiving family planning counselling by hospital, whereas Nyeri counselled 91 percent, Eldoret only provided family planning counselling to 22 percent of the women interviewed (table 6).

It is interesting to note that the sites that were designated as $\mathrm{D} \& \mathrm{C}$ sites in the baseline performed better, in most cases, than the MVA sites implementing the same model. One cannot say that there is a causal relationship, and as noted earlier, these designations were not precise, but this does point to the effectiveness of introducing postabortion care as a package of MVA and postabortion family planning rather than adding these components separately.

\section{Feasibility}

Information was collected on feasibility by focusing on the following components: facility upgrading; staffing; procedural reorganization; and patient flow. The four sites implementing model 1 or 2 had to create a space for counselling on the ward to ensure women's privacy and confidentiality.

The creation of private counselling space was done in different ways, as outlined in table 7. It should be emphasized that in all cases, existing facilities were adapted with limited inputs, i.e. low start-up costs. In spite of this additional investment to set up counselling on the ward, there are other benefits to this model, in addition to the effectiveness described above. With model 1, the same provider can be responsible for a patient's management at the facility, from treatment through to counselling up to discharge. This was viewed as an optimal approach for staffing by many providers. 
Table 7: Description of postabortion family planning counselling rooms

\begin{tabular}{|c|l|}
\hline \multicolumn{2}{|c|}{ Hospital } \\
\hline Mombasa & $\begin{array}{l}\text { Mombasa has a large gynecological ward and undertook } \\
\text { general renovations during the intervention period of the } \\
\text { study. They took advantage of this to designate a small } \\
\text { unused room at the end of the ward for counselling. It was } \\
\text { necessary to purchase chairs, a table, and some other } \\
\text { equipment for this room. }\end{array}$ \\
\hline \hline \multirow{3}{*}{ Kisumu } & $\begin{array}{l}\text { Kisumu already had a minor theatre adjacent to the ward } \\
\text { where they perform evacuations. They used the front part } \\
\text { of this room for counselling. As this room already had a } \\
\text { desk and chairs, there were no additional supplies needed. }\end{array}$ \\
\hline \hline Makuru & $\begin{array}{l}\text { Nakuru set up a partitioned space for providing counselling } \\
\text { on the ward, as there was no available room to use for this } \\
\text { purpose. Funds were needed to build the partitioning and } \\
\text { purchase a table and chairs. }\end{array}$ \\
\hline \hline \multirow{6}{*}{ Meru } & $\begin{array}{l}\text { Meru gynecological patients are in one section of the large } \\
\text { female ward. They took some time to begin counselling on } \\
\text { the ward, but after the purchase of a desk and chairs with } \\
\text { project funds, they designated a space that had been used } \\
\text { by staff for tea breaks as the counselling room, and this has } \\
\text { worked well. }\end{array}$ \\
\hline
\end{tabular}

All sites needed to reorganize procedures somewhat, as postabortion family planning was new. Sites offering services on the ward were all able to obtain contraceptive methods (the combined pill, injectables-- Depo Provera and sometimes Noristerat-- and condoms) from the $\mathrm{MCH} / \mathrm{FP}$ clinic at the hospital. This has not proved to be a problem for any of the sites. However, it is a consideration for other institutions that might choose to implement postabortion family planning and do not have supplies readily available on site. These facilities would have to identify alternative methods of obtaining and maintaining a supply of family planning methods.

Patient flow is also affected by the model of postabortion family planning. This is particularly noticeable in Nyeri, where patients are treated typically within a couple of hours after they arrive at the hospital. However, they must wait until the morning to be escorted as a group to the $\mathrm{MCH} / \mathrm{FP}$ clinic to receive family planning services. This adds to the time they spend in the hospital. There is more flexibility 
with provision of postabortion family planning when these services are offered on the ward.

\section{Acceptability}

Providers were asked about the timing, staff and location of postabortion family planning services. Almost all found the timing (90 percent), which was typically after treatment and before discharge, and the staff delivering the services (93 percent) to be appropriate. Location, however, was not acceptable according to 23 percent of providers interviewed. Of these 24 providers, 21 were at sites offering services in the family planning clinic (i.e., model 3 sites). The problem most commonly mentioned ( 71 percent of the 24 providers) was that the distance from the ward to the family planning clinic is too long which is a burden to both patients and staff. Though this model worked well in Nyeri, many of the providers there said that they would prefer to offer postabortion family planning on or near the ward. Patients were also asked about the acceptability of the details of the new services. Almost all (98 percent) found the timing acceptable, while all (100 percent) said that the location was acceptable.

Many of the providers interviewed (58 percent) have new responsibilities since the introduction of improved postabortion care services. The majority ( 89 percent) find these responsibilities acceptable. Of the seven providers who do not, five said that they feel that they are overworked. These new responsibilities include counselling patients on family planning, assisting in MVA and maintenance of equipment, escorting patients to the $\mathrm{MCH} / \mathrm{FP}$ clinic, training other providers on the job in postabortion care and providing pre-procedure counselling.

\section{Quality of care}

In examining quality of care of postabortion family planning services, we focus on information exchange and method choice. Almost all women felt that the staff providing family planning counselling to them were both acceptable (99 percent) and easy to understand ( 99 percent). Most said that the length of the consultation was about right ( 89 percent), while eight percent felt that it was too short, and three 
percent said it was too long. Of the 59 percent of women who said that they had questions, 90 percent said that they were given an opportunity to ask them, and almost all of these women (94 percent) felt that they received a satisfactory response to their questions.

About two-thirds (64 percent) of women who received a family planning method left the hospital with the combined pill. The second most common method was the injectable (20 percent), followed by the condom (11 percent), while a few women chose Norplant ${ }^{\circledR}$ implants, the IUD or female sterilization. This method mix did vary somewhat by model, with fewer women at model 1 sites receiving the pill (55 percent as compared with 68 and 73 percent for models 2 and 3, respectively) and more women at model 1 sites receiving condoms (14 percent as opposed to nine and eight percent at models 2 and 3, respectively). A similar proportion at all sites received the injectable $(19,23$ and 19 percent, respectively, for the three models).

Figure 10

Information provision on chosen method: Postabortion Care and Situation Analysis Studies

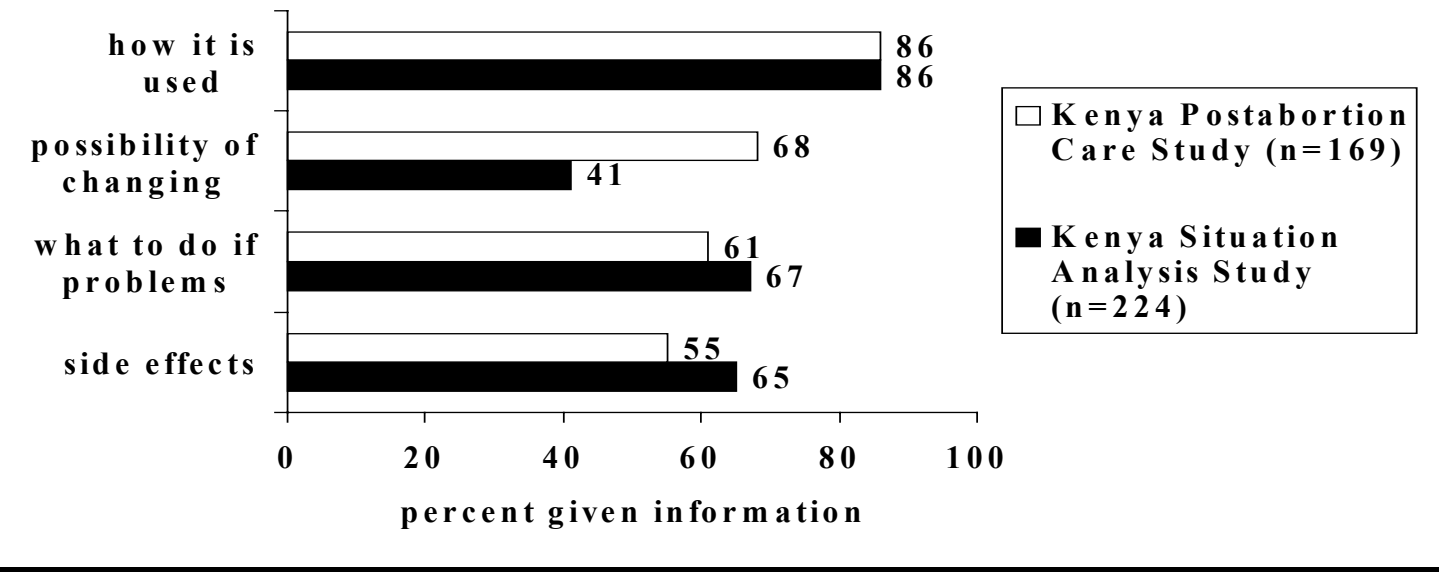

Figure 10 indicates that most women were told how their chosen method is used, and about the possibility of changing methods. However, just over half of women were told about possible side effects, which could be a problem in continuation if women are not told what to expect in using their method. These results are fairly similar to data from the 1995 National Situation Analysis Study in 
Kenya, ${ }^{19}$ although postabortion clients were told much more frequently about the possibility of changing methods and were less frequently informed about possible side effects. Most women (78 percent) were told about methods other than the one they received. Although 14 percent would have liked to use a different method than the one they received, only four percent were disappointed that they did not get this method.

Quality of care on the above indicators varied by model, with model 3 consistently performing better than both models 1 and 2. For example, 71 percent of women were told about side effects of various contraceptive methods at model 3 sites, while this proportion drops to 51 percent for model 1 and 45 percent for model 2 sites. Similarly, 79 percent at model 3 sites were told what to do if they experienced any problems with the method, 64 percent received this information at model 1 sites and only 38 percent at model 2 sites. It is worth noting that there was variation between sites, and in fact, one of the model 1 sites performed as well as the model 3 sites.

\section{Cost}

The MOH made a decision to promote model 1 in expansion of postabortion care services based on the above factors, so a detailed cost analysis was not conducted. However, experiences from this study indicated that the primary issue around the cost of postabortion family planning involved start-up costs for these services. The actual process of providing PAFP, in terms of labor and supply costs, did not seem to vary significantly.

The start-up costs can vary depending on the set-up of the site planning on initiating these services. It is recommended that any site planning to introduce postabortion family planning should conduct a needs assessment to address the following three questions to determine the costs involved in setting up postabortion family planning:

19 Ndhlovu, Lewis, Julie Solo, Robert Miller, Kate Miller, Achola Ominde. An Assessment of 
1. What is the staffing on the ward and what kind of training do these staff have?

2. What kind of resources would be necessary to create a private space on or near the ward for counselling?

3. Could family planning commodities be accessed for the ward, and if so how?

The costs of setting up services will vary depending on the answers to these questions. For example, if the staff do not have any training in family planning, there will be higher costs in providing training, or the facility will have to consider transferring staff with this training (if they are available) to the ward. In the case of the second question, if there is space available, then it is fairly easy and inexpensive to set up a counselling room on the ward. However, in some settings this might not be feasible, or even a relatively small input of US\$250 could be prohibitive. Finally, the question of making methods available is important to providing the full range of services to women. Family planning methods were easily available on site in Kenyan $\mathrm{MOH}$ hospitals, but in cases where they are not, there would be additional costs to the facility to develop logistics systems to obtain and maintain a supply of methods. However, even if methods are not available on site, it is still important to provide counselling and then refer women to facilities where they could receive methods.

\section{Summary: Which Model Works Best?}

Model 1 (provision of postabortion family planning on the ward by ward staff) was the easiest to set up, the most effective and the most acceptable of the three models. Model 3 ranked highest on various indicators of quality of care, though one of the model 1 sites performed almost as well. At sites implementing models 2 and 3, providers expressed the idea that it would be preferable to have ward staff offer postabortion family planning on the ward - that is, to shift to model 1. Overall, we recommend that model 1 be implemented at sites when possible and note that added emphasis may need to be placed on family planning counselling during the training of gynae ward staff. This model also had the unintended effect of more easily incorporating men into the counselling process, as described in the next section. 


\section{Male involvement/ Partner Communication}

In the baseline research, it was found that 41 percent of women were accompanied by their husbands/partners to the hospital. Based on this, as well as increasing interest in involving men in reproductive health care, it was decided to interview men as part of the post-intervention research. Similarly, in the postintervention period, 42 percent of women were accompanied by their husband/partner. Almost one third (29 percent) of women's husbands/partners were interviewed during the post-intervention field work. In addition to showing a great deal of interest and concern in learning more about their wives'/partners' conditions, the vast majority were also very interested in receiving family planning information. It should be noted that not all husbands/partners were interviewed, but only the ones who were available by their presence at the hospital. Therefore, this sample is not necessarily representative of all partners of incomplete abortion patients.

The men were generally aware of the problems that made their wife/partner come to the hospital. Just as in the interviews with women, vaginal bleeding and cramping/abdominal pain were most commonly mentioned. Only 14 percent of men said that they received any information about their wives' condition, and almost all who did not (94 percent) would have liked to (figure 11). They were primarily interested in learning about what caused the problem ( 82 percent) and how to avoid the same problem in the future ( 47 percent).

Most men approve of family planning (88 percent), while 11 percent disapprove and one man was not sure. Interestingly, when women were asked if they thought that their partners approved of family planning, only 60 percent said that he approves, while 23 percent said he disapproves and 17 percent did not know. Some of the researchers did indicate that they felt sometimes there was some courtesy bias with the men trying to say what they thought the researcher wanted to hear. 


\section{Male involvement in postabortion care}

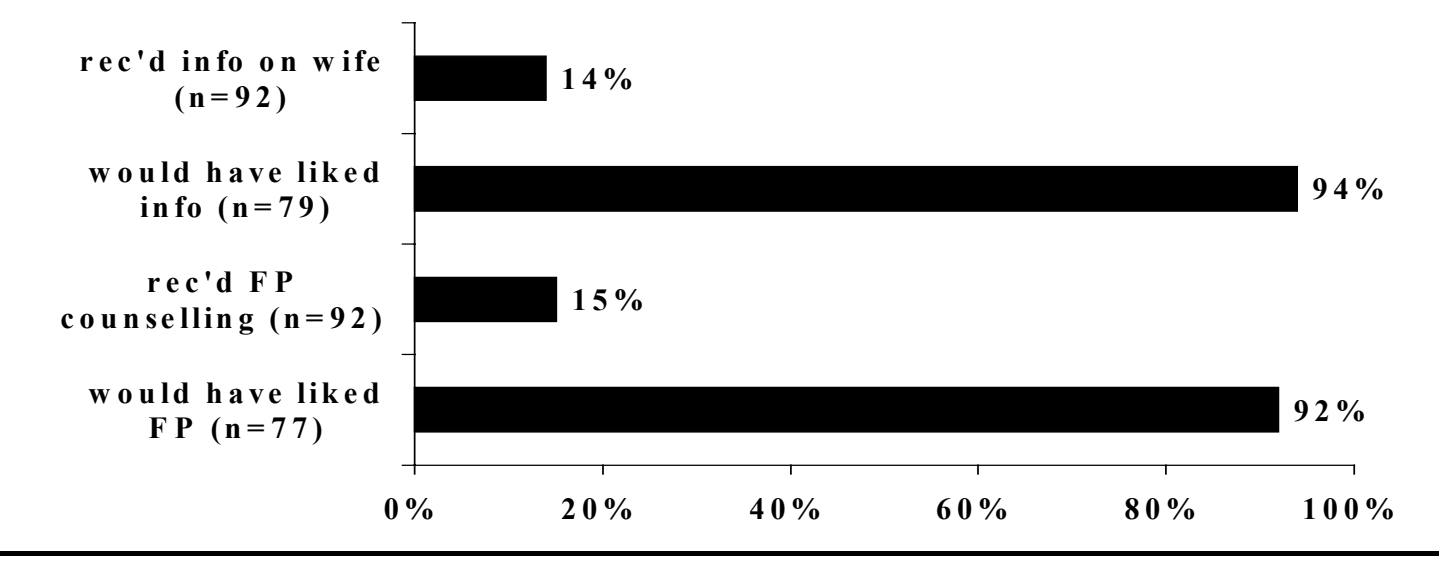

Very few men (15 percent) received family planning counselling. It is actually quite interesting that any men received counselling, as this is rarely done anywhere and was not officially part of the intervention. Almost all of these men (10 of 14) were in Mombasa. The staff at this hospital had decided that there was a need to target men, since many women noted that before they could accept a family planning method they needed to consult first with their husband. Therefore, when men were present, the staff counselled couples together. This was an unanticipated benefit of providing of family planning services on the ward; gynae ward staff have greater access to men there, as compared with the $\mathrm{MCH} / \mathrm{FP}$ clinic staff, since few men ever go to the clinic.

Mombasa has begun to meet a need that exists elsewhere as well; of the men who did not receive family planning counselling, almost all (92 percent) would have liked to (figure 11). In addition, 93 percent of women would have liked to have their husband/partner receive these services. All of the men who received counselling received it together with their wife/partner as a couple, and most (86 percent) who would have liked to have received counselling would have preferred this to be together as a couple. A somewhat lower proportion of women (72 percent) would like to be counselled together with their partner, while 20 percent would like the counselling to be separate (15 percent of men preferred separate). It is important to 
emphasize that women should always be consulted first to determine whether they wish to have their partner included in the counselling.

\section{Challenges in Implementation of Postabortion CaRe}

Staff were asked whether they had experienced any problems in implementing the improved postabortion care services. Just over one-third (35 percent) said that they had. This varied significantly by hospital $(\mathrm{p}=.0007)$, with 80 percent of providers at Eldoret saying that they had experienced problems as compared with between 10 percent and 39 percent at the other five hospitals. The problems most commonly mentioned were: lack of enough staff (16 providers); lack of enough equipment, supplies, drugs, etc. ( 8 providers); lack of a counselling room ( 8 providers); and the long distance between the MCH/FP clinic and the gynecological ward (8 providers).

While almost half (46 percent) of the 37 providers who said they were experiencing problems were able to address them adequately, 19 percent said they were currently trying to address the problems, and 35 percent said they were not able to address them adequately. Some of the ways that problems were addressed included allocation of a nurse specifically to the MVA room or setting up a counselling room on the ward. Others felt that problems could not be addressed due to staff shortages or lack of time. The most difficult problem to address was the lack of enough staff.

In addition to these problems, several issues arose in the course of introducing and monitoring the new services, primarily regarding staffing. First of all, there was the problem of staff transfer. At many of the sites, a number of the providers trained were transferred relatively soon after the training. This created an extra burden for the staff that remained. In addition, because a limited number of staff were trained, there were some tensions between those who were trained and those who were not. This led to a problem of ownership of the project, as explained in the following:

"the nurses concerned were the trained ones. The ones not trained are not concerned with the program at all. The nurses not trained believe that the program belongs to the trained nurses only." 
Some staff believed mistakenly that those who were trained were actually being paid to implement the new services, even though they were not. For example, at one site, staff from other units commented about the gynecological ward staff and the postabortion care project saying that "their palms must have been well and truly greased otherwise they would not be showing such dedication towards project work."

This all points to the importance of institutionalizing on site training and making these services fully part and parcel of ward services rather than maintaining them as separate and as a special project.

\section{SustainabiLity}

Staff at the hospitals were asked in the structured interview whether they thought that MVA and postabortion family planning services would continue. In addition, the Medical Superintendent and the Matron were asked about the sustainability of these services as part of the feasibility instrument. In general, providers are satisfied with these improved services and are optimistic that they will continue. The Medical Superintendent and Matrons stressed the advantages of MVA over $\mathrm{D} \& \mathrm{C}$, in that it is more efficient, reduces congestion on the ward, is cheaper in terms of time and money, more convenient and less traumatic.

Of the 78 providers currently performing or assisting with MVA services, 71 percent feel that the hospital will continue to be able to provide MVA over at least the next year, while 18 percent stated that it depends on certain factors, nine percent think services will not continue, and three percent do not know. They feel that services will continue because the instruments are currently there (32 percent), they have seen the positive aspects of MVA (13 percent), and there are trained staff (13 percent).

The main problems identified with sustainability of MVA services were:

- maintaining supplies of kits. The primary issue that providers identified regarding sustainability of MVA services is the need for assured resupply of kits. Some suggested that these kits be purchased centrally and then supplied to the sites. Many felt that cost sharing money could be allocated to cover the cost of the kits. 
- turnover of trained staff. Providers said that this could be dealt with through training staff on site.

- shortages of consumable supplies, such as gloves and disinfectant. The issue of supply shortages is a widespread one, and is currently being addressed at many sites by having patients buy their own supplies.

Providers were even more optimistic about the sustainability of postabortion family planning services. Most ( 89 percent) felt that these services would continue during the next year, while only one percent said they would not, six percent said it depends, and five percent did not know. Some of the reasons cited by providers included the fact that it has become part of the hospital routine (17 percent), the dedication of the staff (14 percent) and that more providers are getting trained on the job (20 percent). This continuity does however depend on whether or not supplies remain constant ( 24 percent).

In order for both MVA and postabortion family planning services to continue it is essential for hospitals to institute on the job training. Only a limited number of providers were trained at each site for the purposes of this study. Some of the sites have already gone ahead and trained others, and this must be encouraged and continued. MVA is already a component of medical training at Kenyatta National Hospital in Nairobi but a comprehensive package of PAC services is not presented. Neither nurses nor Clinical Officers receive PAC training as part of their standard curriculum, yet these are key providers who must have the skills to provide quality services, particularly in settings where physicians are few in number. However, even if PAC were to be institutionalized immediately in pre-service training for all relevant cadres, there would still be numerous providers already working who would need to be trained in these skills. Thus a combination of pre-service and in-service training would effectively integrate PAC skills into the existing health system. 


\section{DISSEMINATION WORKSHOP AND EXPANSION PLANS}

A dissemination workshop was held on September 11-12, 1997 in Nairobi with over 80 participants from all over the country, including representatives from the six hospitals, the Division of Primary Health Care, Provincial Medical Officers and many organizations working in the reproductive health field. There was a great deal of enthusiasm regarding the success of the project, and after the presentation of findings, participants came up with provincial level plans for expanding PAC services. Essentially, each of the six sites will proceed with an expansion plan involving three key steps:

1. conducting baseline needs assessments at each new site where PAC will be implemented;

2. training selected providers in both MVA and postabortion family planning and upgrading sites;

3. using existing systems and personnel to conduct follow-up evaluation and support visits to trained personnel.

The Population Council's Africa OR/TA Project II will continue to provide technical assistance to the Division of Primary Health Care (DPHC) in planning and initiating this expansion, and will also assist in procuring additional funding for expansion activities. Since the dissemination workshop, the Population Council has helped to organize a series of collaborative meetings with the DPHC and various other organizations, including AVSC, JHPIEGO, Pathfinder and Ipas, to coordinate technical assistance activities to assist the DPHC in fulfilling their goal of initiating PAC services in all $\mathrm{MOH}$ hospitals. It is expected that the success of this program in Kenya can also inform regional initiatives in improving postabortion care. 


\section{FinAl RECOMMENDATIONS}

1) Implement postabortion family planning services on the gynecological ward by ward staff given the effectiveness, feasibility and acceptability of this model.

2) Continue postabortion care services at the six hospitals included in the study and expand training and services to other sites. These services should be introduced as a comprehensive package of both MVA and postabortion family planning.

3) Provide regular PAC updates to all who have been trained.

4) Institute and encourage on-the-job training so that services can continue uninterrupted even when trained staff are transferred to other wards or sites. This will also make comprehensive PAC an integral part of hospital services.

5) Institute PAC into pre-service training for Clinical Officers (COs) and nurses. These providers are needed to ensure that quality services are offered to women on a continual basis.

6) Include equipment and supplies necessary for PAC services in health budgets, both at the central and individual hospital levels.

7) Emphasize pain relief during a woman's care and assess her level of pain before the MVA procedure. Counselling and reassurance are important aspects of pain management, as is the use of anti-inflammatory oral analgesias given before the procedure and paracervical block during the procedure. Anxiolitics should be available for women who need more pain relief.

8) Utilize existing systems for ensuring a continuous supply of MVA kits. Using cost sharing funds is one mechanism. MVA kits should be included in the MOH's essential supplies list so that they are regularly available in MOH warehouses.

9) Emphasize information provision in the training curriculum so that providers equip women with the information they need about their health status before they are discharged from the hospital.

10) When consented to by the woman, involve men in the postabortion care process so that they receive information about their wife/partner's health condition and family planning counselling.

11) Develop and provide IEC at the community level so that information about how to prevent an unwanted pregnancy, signs and symptoms of abortion complications, and services available at the hospital are known to all. 


\section{Appendix 1: Abortion Case Studies: Women Tell Their Stories}

The information presented in this report was collected primarily through structured interviews. In addition to these quantitative data, the researchers often recorded the discussions they had with women while conducting these interviews. The trends presented in this report illustrate women's experiences at the hospital, while the qualitative information gives a picture of women's experiences before they arrived at the hospital. The following are a sample of these stories. Of the 16 stories presented, 11 are examples of induced abortions and five are spontaneous abortion experiences.

These case studies indicate clearly the need to address the problem of abortion in the community, not just in the hospital. In addition, they highlight many important issues, including the following:

- Though the majority of women seeking treatment of incomplete abortion at the six hospitals in the study had experienced induced abortions, many women also arrived after experiencing a spontaneous abortion;

- Misconceptions exist in the community regarding family planning, including the belief that family planning use leads to infertility;

- For induced abortions, women tend to go to "quacks" or private doctors, or less frequently induce the abortion on their own;

- Induced abortions are typically performed by inserting something (a rubber straw, a catheter and a cannula were among the items mentioned) into the uterus, or taking pills (malaria pills were most commonly mentioned);

- Although many women would like to see their partner counselled on family planning, it is important to note that there are cases where women do not want family planning discussed with their partners as they do not want them to find out that they are using family planning.

\section{Stories from the baseline (1996)}

$\rightarrow$ a 22 year old single woman with no previous pregnancies who works as a computer operator said that she had never used any family planning method before and that she conceived during her first sexual intercourse. She admitted that she deliberately procured an abortion, for which she paid about Kshs 3,000 because she says that she has "no intention of having a child out of wedlock," yet is not ready to get married as she feels that she's still too young to settle down and raise a family. Eventually she hopes to have two children and preferably in the next 1-2 years (although she claims that MVA procedure was so painful that she has sworn off sex.) She was interested in getting both family planning information and recommendations as to which is the most appropriate method for her to use. [INDUCED]

$\rightarrow$ a 45 year old divorced mother of four who works as a salesperson for a pharmaceutical company and definitely does not want any more children admitted to having had an induced abortion because "the thought of having a child who's the same age as my own grandchild (daughter's child) is 
somewhat disgusting." She explained that together with a few friends, they are in the business of "helping out" young women who may be in "trouble." She further explained that all they do is initiate the process by inserting a catheter into the uterus. Thereafter, they send the woman to the hospital for "completion of the job." In her own case, her "colleague" did it on a Friday evening knowing that by Saturday the process would be complete. However on getting to the hospital she discovered that no procedures were carried out on the weekends. She therefore has to wait until Monday. She admits that by Sunday she was in such pain she almost left to seek alternative treatment. However, this woman knew the importance of getting "cleaned up" and therefore persevered. [INDUCED]

$\Rightarrow$ A 20 year old unmarried woman. She dropped out of school at class 8 and was now a farmer. This was her first pregnancy and though she would want to have 3 children in her life, she says this will only happen when she gets married (she is not sure when). She had a regular partner. Her abortion was induced by a quack at a fee of Kshs 500 which was paid by her boyfriend. When she came to the hospital, her cervix was torn since the quack had used scissors to perform the induction. Asked why she was not using a method at the time she became pregnant with this pregnancy, she said whenever she asked her boyfriend to use a condom he bought a sweet and asked her to eat it with the wrapper on. This, he said is the same way he would feel if he had sex with a condom on. Asked whether she had decided to start using any FP method she said she feared because the pill "can make someone barren." [INDUCED]

$\Rightarrow$ A 23 year old unmarried woman. She had dropped out of school at class 8 and was now a salaried worker. This was her second pregnancy and was an unwanted one since at the time she conceived she was on the pill but had used it incorrectly. She would like to have 2 more children but is not sure when. Hers was a self-confessed induced abortion. She had it done at a fee of Kshs 2500 by a quack at a private clinic. The quack inserted "something" into her vagina. She opted to abort because she has another child who lived at her parents place and she was not married and thus could not afford to take care of the two. She said she did not want the man responsible to know that she was pregnant because he would have insisted that she retains the pregnancy. She said she preferred to wait until later before using contraception after this abortion. [INDUCED]

$\Rightarrow$ A 19 year old unmarried woman with no regular partner. She dropped out of school at class 8 due to lack of school fees and is now working as a house help. This was her first pregnancy. She said she would want to have 2 children but only when she gets married (she is not sure when this will be). She confessed having induced the abortion because her parents are so harsh that she feared that they might even disown her. The induction was done by her girlfriend who inserted a piece of rubber straw through her vagina. She had never used any contraceptives nor did she decide to begin using after the abortion. This is because she feared they would make her infertile. [INDUCED]

$\rightarrow$ A 22 year old unmarried woman with no regular partner. She dropped out of school at class 8 and was now a farmer. This was her second pregnancy. She would want to have 2 more children but is uncertain when this is going to happen. Hers was a self-confessed induced abortion. The induction was done at a private clinic at a fee of Kshs 2000. Something was inserted into her vagina. "The doctor told me it is called a cannula," this woman said. She opted for abortion because she did not want her parents to know about the pregnancy and she could not afford to support the child since the man responsible was a bus conductor whom she had only met once in a stagecoach bus. This woman preferred to wait until later before she could begin using contraception. [INDUCED]

$\Rightarrow$ a 30 year old woman married monogamously who has had six pregnancies and has four living children. This was her second pregnancy loss, with the other one occurring at five months. She was very emphatic that she does not want any more children-she in fact did not want this $6^{\text {th }}$ one-but her husband has insisted on her having another child. She would prefer to get a tubal ligation (TL). She was of the strong opinion that her miscarriage was due to the stress of looking after her last born child who is 1 year and 7 months old (and still breast feeding) and who has continuously been ill. She sounded quite bitter about her pregnancy loss in terms of the fact that she considers it to have been "unnecessary" in the first place, and therefore feels that she need not have gone through the ordeal that she did when she miscarried. She was determined to leave the 
hospital with a method and even requested the providers to "talk" to her husband and convince him that she should be discharged on a method, preferably TL. [SPONTANEOUS]

$\Rightarrow \quad$ A 27 year old woman who had dropped out of school in form 2 in order to get married. She was now a farmer. Altogether she had had 4 pregnancies but had only 2 living children since she had lost 2 of the pregnancies. The other miscarriage had happened less than 5 months before this last one. She had used the pill for a long time and felt that they were the cause of her delayed conception. She wanted to have 1 more child but wanted to wait for more than one year. She is not sure which method she is going to use because she does not want to use the pill again. [SPONTANEOUS]

$\rightarrow$ A 35 year old married woman. She dropped out of school at class 7 and was now a farmer. This was her fifth pregnancy. She had 2 living children because she had lost 3 of the pregnancies. This one had come only 4 months after the other. Before she conceived with this last pregnancy she had not been using any FP method because she desired pregnancy. After the abortion she did not want to use a method either because "my husband says he wants a baby." [SPONTANEOUS]

$\rightarrow$ A married woman aged 35 years. She was now a farmer having dropped out of school at class 4 after her father refused to pay school fees for girls and said he was only going to pay for boys. She had had 6 pregnancies one of which she had now lost. She wanted to have 1 more child after a period of more than 2 years. She did not want to use any FP method after this because her body was "too weak." [SPONTANEOUS]

\section{Stories from the post-intervention period (1997)}

$\Rightarrow$ A 13 year old unmarried girl who had dropped out of school at class 5. She was not even quite sure of her age but the mother clarified. This was her first pregnancy and she had conceived before she received her first menses. She said that she would want to have 3 children in her life. Asked when she wanted this to happen, she said in less than one year from the time of interview. She confessed having induced the abortion by taking an overdose of malaraquins something she had seen her friends do and succeed. She had been brought to the hospital by the mother of the boy responsible for the pregnancy. On family planning, she said she had never heard of any method. At the hospital she was fully counseled on FP but had not received a method by the time of interview since "provider had to talk with the mother first." [INDUCED]

$\rightarrow$ A single woman aged 18 years and unmarried and still in school. This was her first pregnancy. She would want to have 3 children in her life but is undecided when this is going to happen since she is still in school. Hers was an induced abortion. She had her abortion induced at a fee of Kshs 2000. This was paid by the mother of the boy who was responsible for the pregnancy. This was done at a private clinic but the girl did not reveal the method used. The boy too was student. The girl's mother could not let her take a family planning method since FP method are not good for "children like her." She thus went home without a method. [INDUCED]

$\Rightarrow$ A 17 year old woman still in school and unmarried. This was her first pregnancy and she had conceived while using the rhythm method. She confessed having induced the abortion by taking 6 septrins and 4 chloroquins something she had learnt from her peer group. She said she would want 5 children in her life only she is not certain when this is going to happen since she is still in school. She said she had never spoken about FP with her partner and she wanted him counseled. At the hospital, she was counseled on FP and given a method (combined pill). [INDUCED]

$\Rightarrow$ A 20 year old woman, unmarried and with one living child. She would like to have 2 more children but says this will only happen when she gets married (she is not sure when). She had dropped out of school at form 2 and was now a small-scale trader. This was her second pregnancy. She had had the abortion induced by paying a fee of Kshs 500 (she did not disclose where this was done). After this, she was injected (she does not know what she was injected with). She did not have a regular partner and observed that this pregnancy was as a result of her delay to go for the 
injectable when she was due. She left the hospital with a family planning method (injectable). [INDUCED]

$\rightarrow$ A 19 year old woman married with one living child. She had dropped out of school at class 4 and was now a farmer. This was an unwanted pregnancy since she was on a method when she conceived (Norplant implant). Her husband was not aware she was using a method and she did not want him to know. On whether she wanted another child she said this would depend on how her husband behaved She first had to evaluate her husband. They had had a "difficult marriage." She said her husband was a very mean man; "He even rations the food we have to eat every day." As such she saw no future in the marriage. Asked whether she wanted her husband counseled on FP she said she did not want this to happen lest he knows too much and discovers that she is on Norplant . In fact, she pleaded with the interviewer to be very careful when interviewing her husband lest she disclosed the secret. At the hospital a provider advised her to have the Norplant implant removed but she could not hear of it since she did not want to have another unwanted pregnancy. [INDUCED]

$\Rightarrow$ A 22 year old married woman. She had dropped out of school at class 8 and was now a farmer. She had had 3 pregnancies altogether but had only one living child - she had lost the other two pregnancies. This particular miscarriage had come only 4 months after the other. Before she became pregnant with this last pregnancy, she had not been using a method because she desired pregnancy. She said she would like one more child but is not sure when because she felt very weak. She said she would want her husband too to be counseled on FP. She went home with a method (combined pill). [SPONTANEOUS] 